\title{
Photopatternable Electrolytes for Conducting Polymer Actuators
}

\author{
Yong Zhong
}

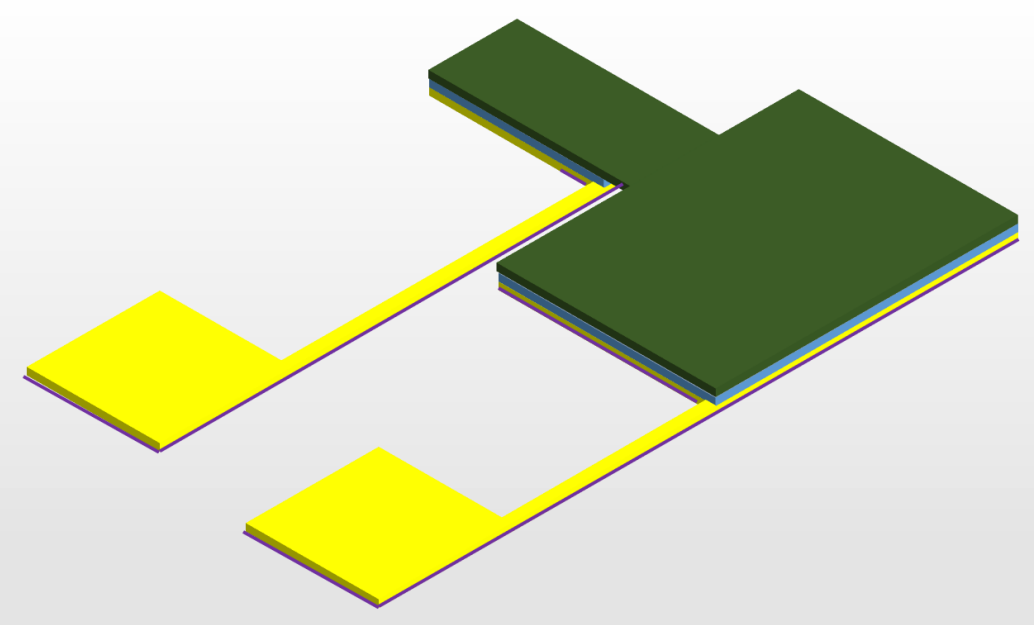


Linköping Studies in Science and Technology

Dissertation No. 2025

Photopatternable Electrolytes for Conducting Polymer Actuators

\author{
Yong Zhong
}

DU UNIVERSITY

Bionics and Transduction Science

Division of Sensor and Actuator Systems (SAS)

Department of Physics, Chemistry and Biology (IFM)

Linköpings universitet, SE-581 83 Linköping, Sweden

Linköping 2019 
Cover: Schematic illustration of a solid-state microactuator fabricated with photolithography (Paper I)

Copyright C Yong Zhong, 2019

Photopatternable Electrolytes for Conducting Polymer Actuators

Printed in Sweden by LiU-Tryck, Linköping, Sweden, 2019

ISSN 0345-7524

ISBN 978-91-7929-978-1 


\begin{abstract}
Electroactive polymers (EAPs) are materials whose physical dimensions can be changed under electric stimulation. They have received huge interests because they can be used as soft, lightweight and silently operating polymer actuators. One significant group of EAPs is conducting polymers. They are driven by the volume variations of the conducting polymers, which are caused by the ion diffusion into/out of the conducting polymer matrix during an electrochemical redox process in the presence of an electrolyte. Over other actuation mechanisms, there are many attractive properties for conducting polymers as actuating materials such as being electrically driven at a low voltage, large generated motion and high stress, and being biocompatible. To miniaturize or fabricate microarrays of these electrochemical actuators that can operate in open air, micropatterns and microstructures of polymer gel electrolyte are desired. In this thesis, we develop photopatternable polymer gel electrolytes based on different routes of polymerization network formation and present their application in conducting polymer (micro)actuators.
\end{abstract}

First, photopatternable electrolyte patterns were developed through free radical photopolymerization of methacrylate monomers as conductive photoresist by a conventional photolithographic process. By immobilizing those electrolyte micropatterns on two electroactive polypyrrole electrodes, a solid-state microactuator was fabricated although a reduced motion was observed as compared to microactuators operating in liquid electrolytes. The result shows a reliable and scalable microfabrication method for conducting polymer based microactuators operating without dipping in a liquid electrolyte using standard photolithography to broaden the microfabrication toolbox. It also shows that advanced solidstate microsystems such as micromanipulators and microrobotics are possible to construct using these on-chip conducting polymer microactuators.

Second, a soft and flexible ionogel combining good photopatternability and reactive surface was developed using free radical mixed mode photopolymerization between thiol and acrylate precursors. The prepared ionogels are well suited to be applied as an ion conducting negative photoresist in traditional photolithography. Micropatterns and advanced microstructures of ionogels are directly fabricated using traditional photolithographic techniques to demonstrate their lithographic capabilities. Its photopatternability has also been successfully proved in a soft lithography process to obtain ionogel film with patterned surface. This new type of ionogel has been demonstrated in the application of electrochromic micropatterns and twisting actuators. A Double Diaphragm Active Polymer Actuator (DDAPA) is also prepared using this novel ionogel to demonstrate its application for active microfluidic components.

Finally, a novel platform to prepare photopatternable ionogels combining active surface and excellent mechanical properties was established with the thiol acrylate Michael addition chemistry. Reaction kinetic of thiol acrylate in ionic liquid was investigated and the results showed that the ionic liquid is also a co-catalyst accelerating the polymerization process, besides acting as the ion source in the in-situ formed ionogel. Three different methods including offstoichiometry, methacrylate addition, and dithiol chain extender addition, were used to develop ionogels with active surface and enhanced mechanical properties. Ion conducting 3-dimensional structures were created by assembling the flexible and surface active ionogel together with the ionogel precursor mixtures as a bonding adhesive. In addition, the photopatternability of the 
prepared ionogels was demonstrated by two micropatterning techniques, photolithography and soft lithography. Two 3-dimensional devices were easily fabricated from a flat ionogel film, a tube actuator with two embedded actuator pairs and a box with two conducting polymer electrodes as a taxel, to show the potential of the reactive surfaces. These interesting results demonstrate that thiol acrylate Michael addition reaction offers a building platform to present various forms of ionogels (flexible and stretchable films, micropatterns, 3-dimensional structures, and bonding adhesive) for different applications in the future electrochemical devices. 


\section{Populärvetenskaplig Sammanfattning}

Elektroaktiva polymerer (EAP) är material som kan ändra sin storlek eller form som svar på elektrisk stimulering. De är mycket intressanta för applikationer som mjuka och lätta polymeraktuator och är dessutom tysta. En viktig grupp inom EAP är ledande polymerer. Dessa aktuatorer drivs av volymförändringen hos de ledande polymererna, vilken är ett resultat av jondiffusionen in i och ut ur den ledande polymermatrisen under en elektrokemisk redoxprocess i närvaro av en elektrolyt. I jämförelse med andra aktuatorer har dessa aktuatorer av ledande polymerer många attraktiva egenskaper såsom att vara elektriskt styrd, ha en låg aktiveringsspänning på $1 \mathrm{~V}$ eller mindre, ge en stor genererad töjning och hög spänning samt god biokompatibilitet. För att miniatyrisera eller tillverka mikroarrayer av dessa aktuatorer i fast tillstånd behövs mikromönster och mikrostrukturer av en polymergelelektrolyt. I denna avhandling utvecklar vi fotomönsterbara polymergelelektrolyter baserade på olika syntesvägar för att bilda polymernätverk och presenterar deras tillämpning i ledande polymer (mikro)aktuatorer.

Till att börja med utvecklades fotomönsterbara elektrolytmönster genom friradikalfotopolymerisering av metakrylat monomerer som jonisk ledande fotoresist genom konventionell fotolitografisk process. Genom att immobilisera elektrolytmikromönster ovanpå det elektroaktiva polypyrrolskiktet uppnåddes fasta-tillstånd-mikroaktuatorer, dock på bekostnad av den möjliga rörelsen jämförd med mikroaktuatorer som rör sig i flytande elektrolyter. Resultatet visar en pålitlig och skalbar mikrofabriceringsmetod för mjuka polymerbaserade mikroaktuatorer med standardfotolitografi för att bredda mikrofabriceringsverktygslådan. Det visar också möjligheten att satsa på komplexa mikrosystem, såsom mikrorobotik och mikromanipulatorer baserat på dessa fasta-tillstånd-mikroaktuatorer.

I den andra delen av arbetet användes en fotopolymerisering av en tiolakrylatblandning för att framställa en ny mjuk och flexibel jongel med en reaktiv yta och en hög jonledningsförmåga. De utvecklade jongelmaterialen är väl lämpade att användas med konventionell fotolitografi som en jonisk ledande negativ fotoresist. Litografiska egenskaper hos materialet möjliggör direkt tillverkning av jonledande mikromönster och 3D-mikrostrukturer med användning av konventionell fotolitografi. Det har också framgångsrikt utnyttjats $\mathrm{i}$ en högupplösande mjuklitografiprocess för att mönstra ytan av jongelfilmen. Tillämpning av denna nya typ av jongel har visats i elektrokroma mikromönster och böjbara mjuka aktuatorer. Denna nya jongel användes också för att konstruera en dubbel diafragma aktiv-polymer-aktuator (DDAPA) för att demonstrera dess tillämpning som ett mikroinjektionsverktyg, en flödesregulator och som en enkelriktad hybridpump för aktiva komponenter inom mikrofluidik.

Slutligen etablerades en ny plattform för att utveckla mikromönsterbara jongeler med justerbara mekaniska och ytegenskaper med hjälp av en Michael additionsreaktion. Polymeriseringskinetiska studier visade att jonvätskan inte bara fungerar som jonkälla utan också som en katalysator i polymerisationen. Jongeler med skräddarsydda ytor och mekaniska egenskaper framställdes med tre metoder: ej stökiometrisk reaktion, metakrylattillsats och tillsättning av ditiolkedjeförlängning. Några 3-dimensionella jonledande strukturer konstruerades genom att binda den flexibla jongelfilmen tillsammans med jongel-lösningen som ett jonbindemedel. Dessutom erhölls mikromönster av jongelerna genom fotolitografi och så kallad mjuk avtryckslitografi. För att illustrera potentialen hos de reaktiva ytorna skapades två 
tredimensionella anordningar från en platt struktur: en rörformig aktuator och en låda med en flexibel elektrod som bildar en "taxel". Dessa intressanta resultat visar att tiolakrylat-baserad Michael-kemi ger en plattform för att tillverka olika former (filmer, mikromönster, tredimensionella strukturer och lim) av jongeler för nästa generation av flexibla elektrokemiska anordningar. 


\section{Publications included in this thesis}

The $\mathrm{PhD}$ thesis is based on the following papers:

(1) Development of polypyrrole based solid-state on-chip microactuators using photolithography Yong Zhong, Staffan Lundemo, Edwin W.H. Jager

Smart Materials and Structures 2018, 27 (7), 074006.

Contribution: Partly conceived the experiment design, performed most of the experiments, major part in writing and submitted the manuscript.

(2) Highly conductive, photolithographically patternable ionogels for flexible and stretchable electrochemical devices

Yong Zhong, Giao T. M. Nguyen, Cedric Plesse, Frederic Vidal, Edwin W.H. Jager

ACS Applied Materials \& Interfaces 2018, 10 (25), 21601-21611.

Contribution: Major contribution to conceiving the experimental design, initiated and performed all the experiments, major part in writing and submitted the manuscript.

(3) Fully disposable active microfluidics enabled by a versatile polymer actuator system for pumps, valves and injectors

Yong Zhong, Daniel Filippini and Edwin W.H. Jager

Submitted to Sensors and Actuators B: Chemical.

Contribution: Major contribution to conceiving the experimental design, initiated and performed all the experiments, major part in writing and submitted the manuscript.

(4) Tailorable, 3D structured and micro-patternable ionogels for flexible and stretchable electrochemical devices

Yong Zhong, Giao T. M. Nguyen, Cedric Plesse, Frederic Vidal, Edwin W.H. Jager

Journal of Materials Chemistry C 2019, 7 (2), 256-266.

Contribution: Major contribution to conceiving the experimental design, initiated and performed all the experiments, major part in writing the manuscript and submitted the manuscript. 


\section{Publications not included in this thesis}

(5) Actuating textiles - next generation of smart textiles

Nils-Krister Persson, José G. Martinez, Yong Zhong, Ali Maziz, Edwin W.H. Jager

Advanced Materials Technologies 2018, 3 (10), 1700397.

(6) Microfabricating carbide-derived carbon-polypyrrole hybrid microactuators

Zane Zondaka, Yong Zhong, and Edwin W.H. Jager

In manuscript.

(7) Chapter 8: Soft actuator materials for textile muscles and wearable bioelectronics

Edwin W.H. Jager, José G. Martinez, Yong Zhong, Nils-Krister Persson

Wearable Bioelectronics, 1st Edition

Editors: Anthony Turner, Alberto Salleo, Onur Parlak. 


\section{Academic Workshops \& Conferences}

EuroEAP 2015, Tallinn, Estonia

June 9-11, 2015

11th Micronano Systems Workshop, MSW2016, Lund, Sweden

May 17-18, 2016

Poster: Development of dry state on-chip microactuators based on polypyrrole

MICACT Training School on Dielectric Elastomer Transducers, EPFL, Neuchâtel, Switzerland September 8-10, 2015

MICACT Training School on Modelling and Ionic EAPs, University of Tartu, Tartu, Estonia January 25-29, 2016

EuroEAP 2016, Helsingør, Copenhagen, Denmark

June 14-15, 2016

Poster: Fabrication of polypyrrole based dry state on-chip microactuators

MICACT Training School on Microfabrication, Linköping, Sweden

January $17-20,2017$

EuroEAP 2017, Cartagena, Spain

June 6-7, 2017

Poster: Micropatterning of solid polymer electrolytes using photolithography

MICACT Training School on Electroactive Polymers, Darmstadt, Germany

January 22-25, 2018

EUROEAP 2018, Lyon, France

June 5-6, 2018

Poster: Tailorable polymer gel electrolytes with reactive surfaces from thiol acrylate Michael reaction for ionic actuator

The World Polymer Congress, MACRO18, Cairns, Australia

July $1-5,2018$

Oral presentation (10 minutes): Flexible gel electrolytes with reactive surfaces for soft electrochemical systems 


\section{Acknowledgement}

It is a great experience to work here as a $\mathrm{PhD}$ student in the division of Sensor and Actuator Systems (SAS) within the department of Physics, Chemistry and Biology (IFM) at Linköping University, Sweden during the past 4.5 years. The research work that I have done during these years is impossible without the help and assistance from all the people with whom I am working together. Their contributions are indispensable for the completion of this thesis and I would like to express my sincere gratitude and appreciation to them.

I would like to thank my supervisor, dr. ir. Edwin Jager, for accepting me as his graduate student and his continuous encouragement and patient guidance throughout the $\mathrm{PhD}$ study. His optimistic attitude and insightful discussion during the weekly meetings have directed my research work in the right direction.

Part of the research work of this thesis has been performed in the Laboratoire de Physicochimie des Polymères et des Interfaces (LPPI) in the Université de Cergy-Pontoise, France from September 2016 to May 2017. The secondment there is a turning point for my PhD study. Help for relocating to France and their scientific discussions and guidance from Prof. Frédéric Vidal, Dr. Cédric Plesse and Dr. Giao T. M. Nguyen are highly appreciated.

I would like to thank my co-supervisors, Prof. Anthony Turner and Dr. Jose Gabriel Martinez Gil, for scientific discussions and revising the thesis.

Special thanks to Dr. Chun-Xia Du for the training and helping in the cleanroom.

I would like to thank for the support from all present and former members in the Sensor and Actuator Systems (SAS) group and previous Biosensors and Bioelectronics group. My special thanks for their invaluable help in the lab go to Prof. Daniel Filippini, Dr. Ali Maziz, Dr. Alexandre Khaldi, Dr. Mike Andersson and Manav Tyagi.

On a personal level, I would like to thank my parents and family for their unconditional support and understanding during my life. 


\section{Table of contents}

Chapter 1 Introduction ___ 1

1.1 Soft actuation in robotics ___ 1

1.2 Aim and outline of the thesis ___ 2

Chapter 2 Conducting polymer actuators ___ 3

2.1 Electroactive polymer (EAP) actuator ___ 3

2.2 Conducting polymers ___ 4

2.3 Synthesis of conducting polymers ___ 5

2.3.1 Electropolymerization ____ 5

2.3.2 Chemical oxidation polymerization __ 6

2.4 Actuating mechanism of conducting polymer actuators __ 7

2.5 Classification of conducting polymer actuators ___ 9

2.5.1 Actuators working in liquid electrolytes___ 10

2.5.2 Solid state actuators ___ 11

2.6 Microactuators ___ 14

2.6.1 Microactuators working in liquid electrolytes ___ 15

2.6.2 Microactuators operating in open air____ 16

2.7 Advantages and disadvantages of conducting polymer actuators ___ 18

Chapter 3 Thiol-ene chemistry ___ 21

3.1 "Click" chemistry ___ 21

3.2 Thiol-click reactions ___ 21

3.3 Thiol-ene coupling chemistry___ 22

3.3.1 Ideal free radical thiol-ene coupling reaction __ 22

3.3.2 Thiol (meth)acrylate free radical mixed mode reaction ___ 23

3.3.3 Catalyst mediated thiol-ene Michael addition___ 24

3.3.3.1 Base catalyzed thiol-ene Michael addition___ 24

3.3.3.2 Nucleophile catalyzed thiol-ene Michael addition ___ 25

3.4 Monomers used in thiol-ene coupling reaction___ 26

3.4.1 Thiol monomers___ 26

3.4.2 Ene monomers____ 27 
3.5 Oxygen inhibition 28

3.6 Properties of thiol-ene based polymer networks 29

3.7 Light induced thiol-ene coupling reaction 30

3.8 Application of thiol-ene coupling reaction in patterning 31

3.8.1 Photolithography 31

3.8.2 Soft lithography 33

3.9 Thiol-ene based polymers for fabrication of microfluidic devices 34

3.10 Thiol-ene photopolymers for 3D printing 34

Chapter 4 lonogels 37

4.1 lonic liquids 37

4.2 lonogels 38

4.3 Properties of ionogels 38

4.3.1 Mechanical and physical properties 38

4.3.2 lonic conductivity 39

4.3.3 Morphology 39

4.4 Classification of ionogels 40

4.4.1 Organic, inorganic and composite ionogels 40

4.4.2 Physical gels and chemical gels 41

4.5 Polymer based ionogels 41

4.6 Photopatternable ionogels 42

4.7 lonogels with 3D microstructures 44

4.8 Functional ionogels 44

4.9 Polymerized ionic liquids 45

4.10 Application of ionogels in soft EAP actuators 45

Chapter 5 Summary of the papers included 47

Chapter 6 Outlook 51

References 53 


\section{Chapter 1 Introduction}

\subsection{Soft actuation in robotics}

The world is currently experiencing a significant demographic change towards a high level of aging population[1, 2]. In almost every country, the number of senior people aged 60 years or over is increasing rapidly and makes up a growing percentage of the total population. Globally, it is projected that the number of senior people is growing to 2.1 billion in 2050 according to the World Population Ageing report from the United Nations (2017). In the coming decades and beyond, the impact of population aging is enormous and multifaceted including shortage of labor supply, lack of adequate welfare care, possible decline in productivity and deterioration of economic growth. Besides designing appropriate policy from the governments, it is imperative to develop advanced technology to ease the negative impacts of ageing population on the human society and global economy. Introducing advanced robotics to human society on a wide scale could be one of the possible solutions. Robots that can be programmed to carry out dangerous and tedious tasks, are becoming increasingly popular in manufacturing facilities to boost the productivity. However, these robots are unsuitable for close interaction with humans especially for senior people because these rigid robots are usually made from hard, noncompliant, and heavy materials such as metal, and they are driven by conventional actuation technologies such as big and noisy motors. In contrast to these conventional robots, soft robots provide an excellent opportunity to interface with humans, and to help human beings in their daily life[3, 4]. The bodies of soft robots are made from intrinsically soft and compliant materials. This allows the robots to readily adapt to different objects for firm grasping and better mobility. They can be deformed easily and absorb much of the energy in case of a collision. Thus, the flexibility and adaptability of soft robots for accomplishing various tasks is greatly enhanced, as well as the interaction with human bodies. In addition, microscale soft robots are important to improve the life quality of human beings as they are needed, for example, to generate gentle stimulation to biological tissues or to perform microsurgery inside human bodies[5]. To achieve the great potential of soft robots, the key challenge is the development of soft actuation technologies that are compatible with the compliant materials used as the body of soft robots. One promising class of soft actuation technologies is the electroactive polymers (EAPs) that can emulate soft biological muscle-like actuation.

Electroactive polymers are defined as intelligent materials whose dimensions or shape are capable to change when subjected to electrical stimulation[6-8]. They have received considerable interests because they can be used as soft, lightweight and silently operating polymer actuators. EAP actuators as an emerging technology can mimic the movement of natural muscles and are described as artificial muscles. The generated biomimetic motion benefits many fields such as soft robotics, tunable optics and acoustics, haptic devices, grippers, manipulators, tactile displays, and biomedical tools[9-11]. There are several types of electroactive polymers suitable for actuation purposes. They are normally categorized into two major groups, electronic EAPs and ionic EAPs, depending on the actuating mechanism. One significant class of ionic EAPs is conducting polymers. They are driven by the volume variations of the conducting polymers, which are determined by the ion diffusion into/out of the conducting polymer matrix during an electrochemical redox process in the presence of an 
electrolyte[12]. Conducting polymer actuators with different configurations (freestanding films, bilayers, and trilayers) and actuation modes (bulk, linear, bending, buckling, and mixed) in different operating environments (in liquid electrolyte solution and open-air) have been developed over the past years. Conducting polymer actuators have unique and diverse properties such as mechanically soft and flexible, lightweight, able to operate at low potentials, large force and strain. Another exceptional feature of conducting polymer actuators is that they can easily be miniaturized with various microfabrication techniques like traditional photolithography, laser ablation and reactive ion etching $[13,14]$. This feature makes them an excellent choice for applications in advanced microdevices such as micromanipulators of living cells and soft tissues, active components in microfluidic systems such as microvalves and micropumps, micromachined light reflector and modulators in optical instrumentation, drug delivery in biomedicine, actuating hinges for microrobotics, and more[15]. However, conducting polymer microactuators especially those open-air operating microactuators are still in a simple bending beam configuration. Complex solid-state microdevices such as microrobots would require multiple and individually controlled microactuators. Meanwhile, the electrical connections to the microactuators are not fully integrated, which still requires the use of macroscopic connectors. A mechanically robust and stable electrical connection that can be integrated in the microsystem and directly formed during its microfabrication process is needed. To develop individually addressable solid-state microactuators with fully integrated electrical connections, a photolithographic process for microactuators working in liquid electrolyte is modified to create solid-state microactuators consisting of two conducting polymer electrodes in a parallel configuration and solid-state electrolyte. The two conducting polymer electrodes are positioned in a parallel configuration on a substrate and ionically connected with a thin pattern of the gel electrolyte, rather than being stacked in a sandwiched configuration. To develop this new microfabrication process for solid-state microactuators, photopatternable solid-state electrolyte compatible with traditional photolithographic process is desired.

\subsection{Aim and outline of the thesis}

This thesis is aimed to design, prepare and characterize photolithographically micropatternable polymer gel electrolyte combining high ionic conductivity and good mechanical properties using novel polymerization techniques. These photopolymerizable electrolytes should be deposited and patterned as easily as a photoresist and integrated into the microfabrication process of conducting polymer solid-state microactuators. In addition, exploitation of these photopolymerizable electrolyte materials in macroscale electrochemical actuation and sensing devices is also aimed.

This thesis includes six chapters, with chapter 1 and 2 focusing on some introductory information about conducting polymer actuators. Chapter 3 gives an overview of the thiol-ene chemistry used to prepare micropatternable solid polymer electrolytes. Chapter 4 is devoted to an overview of ionogels, a type of polymer gel electrolyte based on ionic liquid. Finally, a summary of the attached scientific papers and future perspectives are given in Chapters 5 and 6 , respectively. 


\section{Chapter 2 Conducting polymer actuators}

\subsection{Electroactive polymer (EAP) actuator}

EAP actuators have exceptional properties in structure and functionalities that are derived from combining their electromechanical functionalities with the traditional properties of polymer materials[16]. Specifically, EAP actuators are mechanically soft, flexible and stretchable. Their simple layered structures allow great flexibility in their design and functional versatilities since they are capable to contract, expand, extend, bend, or morph when subjected to external electrical stimulation. They are prepared from simple material composition and can be easily processed and manufactured into different shapes such as films and fibers, and in many cases with low cost. They can achieve large active strains and force with high power density and low noise. Their intrinsic sensing capabilities provide an opportunity to engineer actuators that mimic muscle-like behavior[7]. Therefore, they have been investigated as artificial muscles in a wide range of emerging biomimetic applications, which are difficult to achieve with conventional actuators such as electric motors. EAPs include a large group of polymer materials and they are generally categorized into two main groups according to their actuating mechanism as shown in Figure 2.1[17].

Electronic EAPs are actuating polymer materials whose dimensional variation is activated by electric fields or Coulomb forces. They include dielectric elastomer, electrostrictive graft elastomer, ferroelectric polymer, and liquid crystal elastomer. Taking dielectric elastomer actuators as an example, the actuation is caused by the dimensional changes of a soft dielectric elastomer under the electrostatic forces between two flexible conducting electrodes[18]. Dielectric elastomer actuators have high stress and strain with great energy density. They are fast and efficient and can operate in open air. However, a significant drawback is their need of kilovolts level activation voltage which is close to the electrical breakdown level and may be disadvantageous for many important applications[19].

Ionic EAPs are actuating polymer materials caused by the migration of mobile ions and/or the accompanying solvents. They can be divided further into conducting polymer, ionic polymermetal composite (IPMC), ionic polymer gel and carbon nanotube. The main advantage of ionic EAPs is the low driving voltages $(1-5 \mathrm{~V})$, which is in sharp contrast to the electronic EAPs. This chapter is focused on conducting polymer actuators, which is an important group of ionic EAPs. 


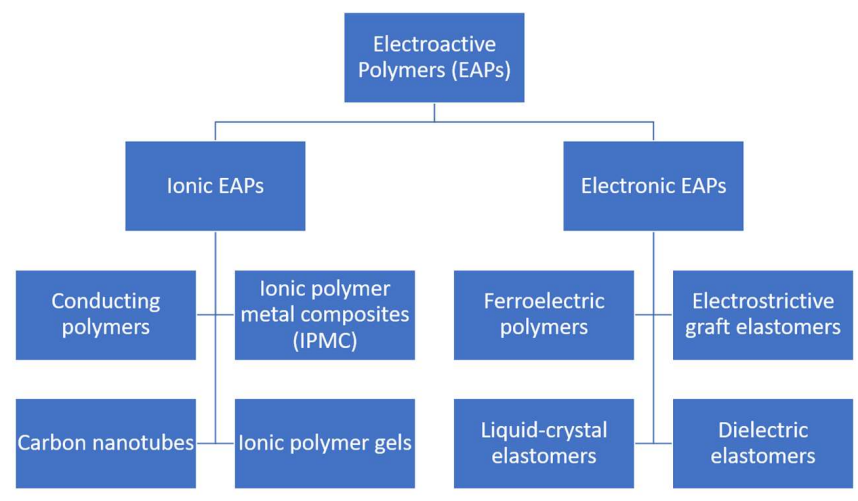

Figure 2.1 Classification of electroactive polymers (EAPs) based on their actuation mechanism[17].

\subsection{Conducting polymers}

Conducting polymers are organic conjugated polymers consisting of alternating single and double carbon-carbon bonds with distinguished electrically conductive properties[20, 21]. In their neutral form, conducting polymers are insulators or poorly conducting semiconductors since they do not have intrinsic charge carriers. To achieve conductivity, the polymeric backbone needs to be oxidized or reduced either electrochemically or chemically by incorporating a certain amount of anionic or cationic species. This process is called doping, which introduces charge carriers able to move along the polymeric backbones, resulting in drastic changes in the electrical conductivities of the polymers. The charges in the doped state are easily shared and delocalized along the backbone as a result of the $\pi$ electron conjugation system. In analogy with silicon semiconductor, the conducting polymers can be n-doped or pdoped[22, 23]. During p-doping, electrons are removed from the polymer chains. Therefore, negatively charged anions are inserted within the positively charged polymer matrix to keep the charge neutrality. During n-doping, electrons are added to the polymer chains and positively charged cations are inserted into the negatively charged polymer to neutralize the charges. The de-doping reactions in both cases correspond to a return to the neutral state of conducting polymers. The p-doped conducting polymer is most commonly used because it is more stable than n-doped conducting polymer. In contract to silicon semiconductor, the doping level of conducting polymer is very high and the doping process is reversible, which can be electrochemically controlled. For instance, the electrons can be reversibly added to reduce the charged conducting polymer and leave the polymer backbone neutral by applying a more negative potential. Depending on the doping state and level, the conductivity of the electrically conducting polymer varies considerably in a wide range of conductivities between the doped and undoped states as shown in Figure 2.3[24, 25]. Besides the conductivity variations, several other properties of conducting polymers are also affected by the dopant level, including volume changes, color, mechanical properties, optical absorption, permeability, hydrophobicity and 
stored charges[26]. These properties enable their wide use in different applications such as supercapacitors, electrochromic devices, transistors, filters, and batteries. The capabilities of volume changes during the doping and dedoping process makes them particularly attractive for electrochemical actuator applications.
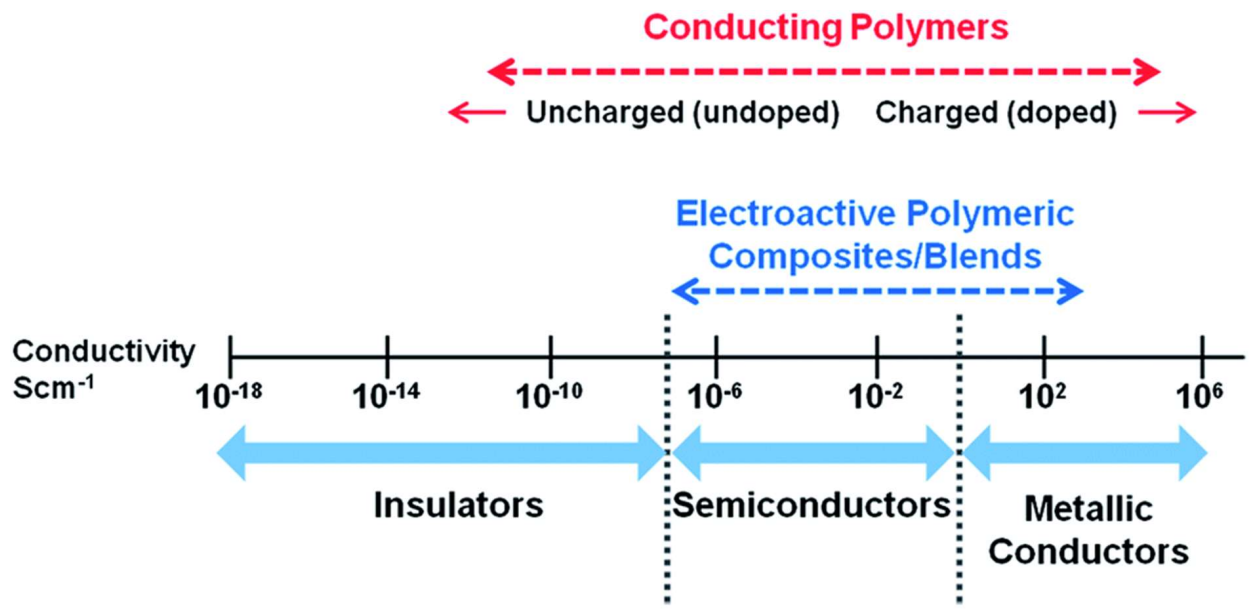

Figure 2.3 The conductivity range of electrically conducting polymers[25]. Published by The Royal Society of Chemistry.

\subsection{Synthesis of conducting polymers}

The most widely studied conducting polymers for use in actuation are polyanilines (PANI), polypyrrole (PPy) and poly(3,4-ethylenedioxythiophene) (PEDOT)[27, 28]. The morphology, doping level, conductivity, molecular weight and volume variations are strongly influenced by the synthesis methods, which generally include the electropolymerization and chemical oxidation polymerization.

\subsubsection{Electropolymerization}

Electropolymerization is a technique to carry out polymerization reactions in the presence of electrodes that add or remove electrons[29]. The potential or current are usually applied using a potentiostat in a typical three-electrode electrochemical cell, which includes a working electrode (WE), a counter electrode (CE) and a reference electrode (RE). The electropolymerization takes place on the working electrode. The counter electrode is needed for completing the current circuit in the electrochemical cell. The reference electrode is used for 
potential control and measurement as it has a stable and well-known electrode potential. The electropolymerization process is carried out in an electrolyte containing monomers by employing electrochemical techniques such as the galvanostatic or potentiostatic method or cyclic voltammetry. The electropolymerization of conducting polymers proceeds via a mechanism of monomer oxidation, dimerization, and the following growth of oligomers and polymers[30]. Anionic dopants as counterions are inserted during the electropolymerization process to neutralize the positive charges on the oxidized polymer chains. The insoluble conducting polymer chains precipitate out of electrolyte solution and are deposited on the working electrode surface where the oxidation of monomers starts. This synthesis method allows the control of some critical polymerization parameters, such as the type of counterions, the polymerization time and temperature, the applied potential or current, and the polymerization solvent[31]. These electropolymerization conditions strongly affect and allow to precisely tune the electrical conductivity, morphology, mechanical properties, doping level, crosslinking density, film thickness and uniformity, polymerization kinetics, and subsequent actuation properties of the resulting conducting polymer films. However, one drawback of electropolymerization is that conducting polymer film can only be obtained on electrically conductive electrodes such as metal surfaces.

\subsubsection{Chemical oxidation polymerization}

The chemical oxidation polymerization is an easy and convenient technique for conducting polymer synthesis[32]. With this method, conducting polymer film can be deposited on any surface including non-conductive substrates. This method is realized through oxidation of monomers with the help of an oxidant such as iron (III) chloride ( $\left.\mathrm{FeCl}_{3}\right)$ or iron (III) tosylate $\left(\mathrm{Fe}(\mathrm{OTs})_{3}\right)[33,34]$. An example of conducting polymers synthesized by chemical oxidation polymerization is the commercially available conducting polymer PEDOT:PSS (poly $(3,4-$ ethylenedioxythiophene) polystyrene sulfonate), which is obtained through chemical oxidation polymerization of the hydrophobic EDOT monomer in the polystyrene sulfonic acid (PSS) aqueous solution. The resulting PEDOT:PSS polymers are dispersed in the aqueous mixture as colloidal gel particles in which hydrophobic and positively charged PEDOT core is surrounded by hydrophilic and negatively charged PSS shell. The PSS in the PEDOT:PSS complex serves as the counterions for the oxidized PEDOT backbones and stabilizes the insoluble PEDOT polymers in the aqueous solution. The hierarchical structures of PEDOT:PSS complex are shown in the Figure 2.4[35]. The aqueous colloidal dispersion of PEDOT:PSS has the advantage of facile processing for conducting polymer film or fiber structures through various techniques, such as dip coating, drop casting, spray coating, electro/wet-spinning, inkjet printing and spin coating, which are not possible with conducting polymers synthesized through electropolymerization method[36-38]. Another form of chemical oxidation polymerization is vapor phase polymerization (VPP). In this method, the monomer is introduced in the vapor phase to the oxidant covered substrate at reduced pressure[39]. 

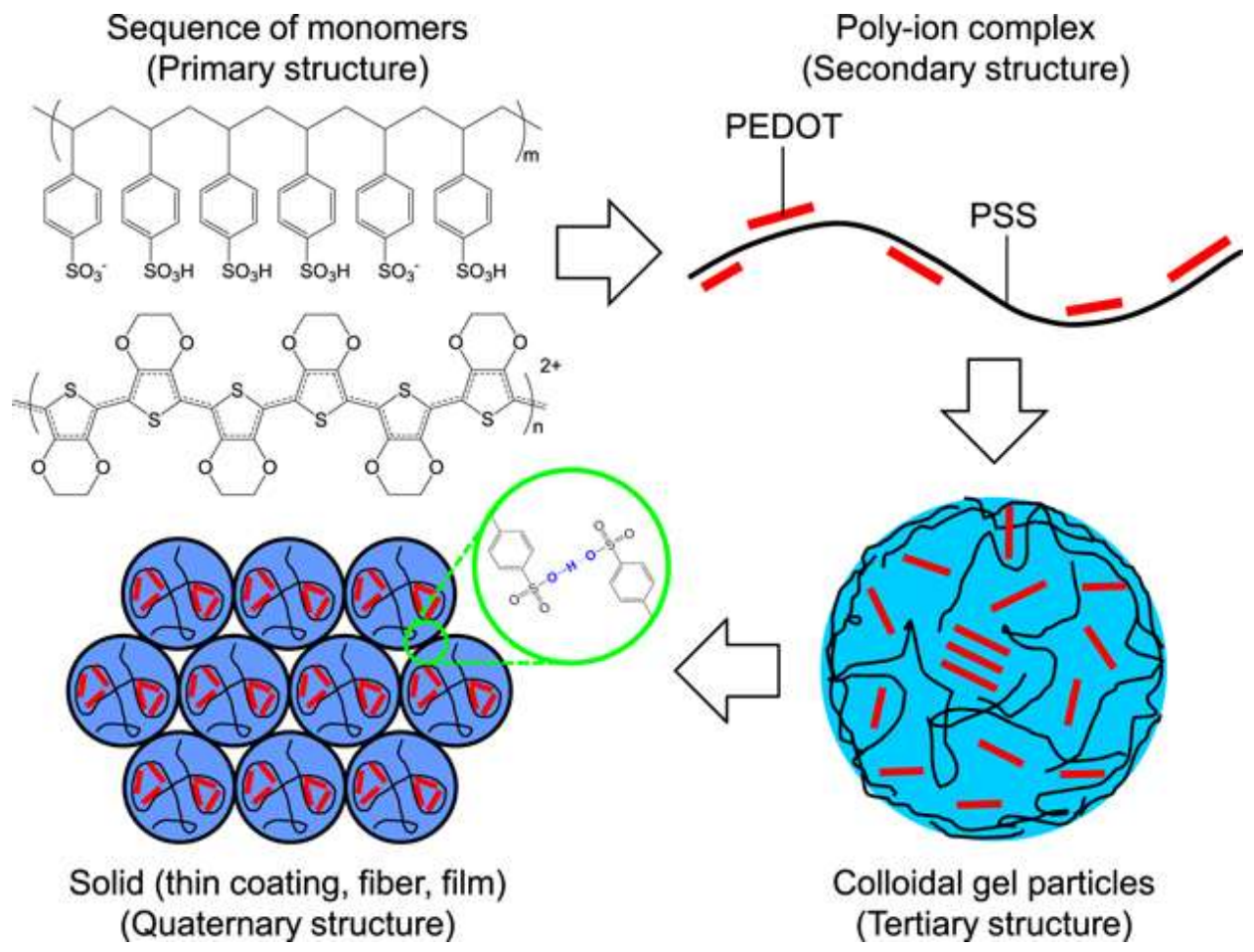

Figure 2.4 Hierarchical structure of colloidal PEDOT:PSS dispersion. Reprinted with permission from[35]. Copyright (C) 2014 IOP Publishing Ltd.

\subsection{Actuating mechanism of conducting polymer actuators}

The dimensional variation of conducing polymers, which is a result of the electrochemical redox process, is the driving mechanism behind conducting polymer-based actuators[40, 41]. The electrochemical redox process adds or removes electrons to the polymer backbone. As a result, cations or anions from the electrolyte materials are incorporated into or expelled from the polymer matrix in order to maintain the charge neutrality. The mass flow of ions between the polymer matrix and the surrounding electrolyte causes swelling or contraction of the conducting polymer matrix, which thereby converts electrical energy into mechanical energy. Determined by the mobility of anions and cations, and the type of the electrolyte used, conducting polymer actuators can be driven by anions, cations or mixed ions. For the conducting polymer doped with large and immobile anions, the electrochemically generated charges on the conjugated polymeric backbone are compensated by the small mobile cations in the electrolyte[42, 43]. The cation-driven mechanism is shown in Equation 1 and 2 with most studied PPy(DBS) actuators in NaDBS electrolyte as an example[44, 45]. $\mathrm{PPy}^{+} \mathrm{DBS}^{-}$represents the doped/oxidized polypyrrole polymer and $\mathrm{PPy}^{0}(\mathrm{NaDBS})$ the undoped/neutral state. DBS- 
(dodecylbenzenesulfonate) indicates the inserted dopant ion during polypyrrole synthesis process and trapped within the polymer matrix and $\mathrm{Na}^{+}$indicates the inserted sodium cation during reduction of $\mathrm{PPy}^{+} \mathrm{DBS}^{-}$.

$$
\begin{array}{ll}
\mathrm{PPy}^{0}(\mathrm{NaDBS}) \rightarrow \mathrm{PPy}^{+} \mathrm{DBS}^{-}+\mathrm{Na}^{+}+\mathrm{e}^{-}, & \text {Oxidation } \\
\mathrm{PPy}^{+} \mathrm{DBS}^{-}+\mathrm{Na}^{+}+\mathrm{e}^{-} \rightarrow \mathrm{PPy}^{0}(\mathrm{NaDBS}), & \text { Reduction }
\end{array}
$$

During oxidation, large $\mathrm{DBS}^{-}$anions are immobile inside the polymer matrix due to low diffusion rate while the small $\mathrm{Na}^{+}$ions are easily expelled. Therefore, a volume contraction is generated. In the case of reduction, the immobile DBS- ions cannot leave, so small $\mathrm{Na}^{+}$cations are inserted into the polymer matrix and a volume expansion can be observed.

For conducting polymers doped with a small mobile anion, the volume of conducting polymers increases during oxidation and decreases during reduction[46, 47]. The anion driven process is described by using PPy(TFSI) as an example (Equation 3 and 4). $\mathrm{PPy}^{0}$ denotes the neutral/undoped conducting polymer. $\mathrm{PPy}^{+} \mathrm{TFSI}^{-}$indicates the doped/oxidized conducting polymer.

$$
\mathrm{PPy}^{0}+\mathrm{TFSI}^{-} \rightarrow \mathrm{PPy}^{+} \mathrm{TFSI}^{-}+\mathrm{e}^{-}, \quad \text { Oxidation }
$$

$$
\mathrm{PPy}^{+} \mathrm{TFSI}^{-}+\mathrm{e}^{-} \rightarrow \mathrm{PPy}^{0}+\mathrm{TFSI}^{-}, \quad \text { Reduction }
$$

When an oxidative voltage is applied, the conducting polymers $\mathrm{PPy}^{0}$ lose electrons and become positively charged. Mobile anions TFSI ${ }^{-}$are incorporated into the polymer matrix to neutralize the electrical charge, leading to volume expansion. During reduction, positive charges on the conducting polymers are removed. Anions $\mathrm{TFSI}^{-}$are leaving from the conducting polymers and the volume of conducting polymers contracts.

The volume changes of conducting polymers via these two different pathways are illustrated in Figure 2.5[48]. In general, conducting polymers undergo only one major ion flow pathway. However, when both cations and anions have similar size or mobility, the two ion flow mechanisms can occur simultaneously or consecutively[49]. This results in opposite volume variations and affects the final net volume changes. This is clearly unfavorable for actuator application, and a dominant ion species during the redox reaction is preferred.

In addition to the ion flow, the electrolyte solvent also affects the volume changes of conducting polymer during electrochemical redox process. As the ions are solvated in the electrolyte, solvent molecules accompanying the ions are also inserted into or expelled from the polymer matrix and account for much, if not most, of the volume changes. Meanwhile, insertion of solvent molecules can take place independently of ion transport due to osmotic pressure effect, which also contributes to the total dimensional changes[50,51]. 


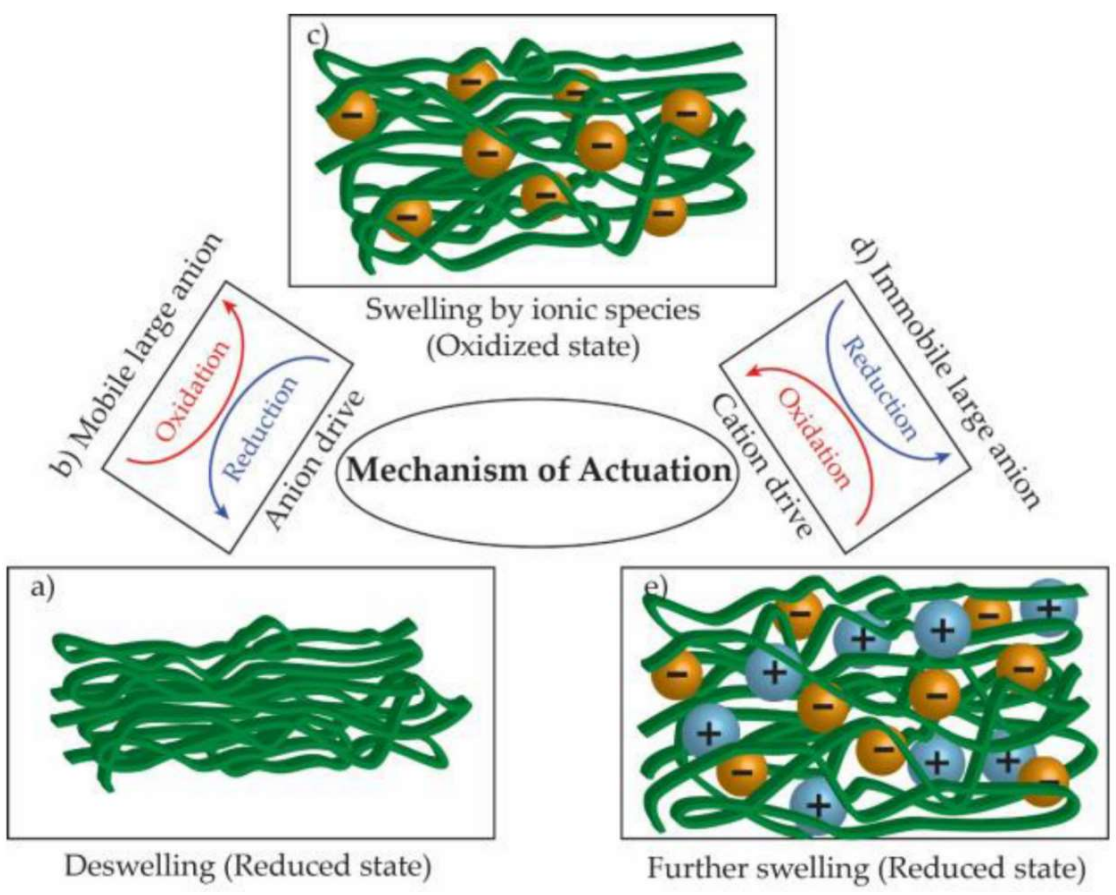

Figure 2.5 Actuation mechanism in conducting polymers via two different pathways: (b) anion driven and (d) cation driven[48].

\subsection{Classification of conducting polymer actuators}

Conducting polymers with the capability of reversible dimensional change are then used as the active part to construct various electrochemical actuators with different configurations. These actuators can be categorized based on conducting polymer materials (polyanilines, polypyrrole, PEDOT), number of structural layers (freestanding, bilayers, trilayers), motion type (bulk expansion, linear, bending, buckling) and dimensions (microscale, macroscale). Based on the operating environment, conducting polymer actuators operate in open air or in a liquid environment. Figure 2.6 summarizes six types of conducting polymer actuators with different configurations[52]. 

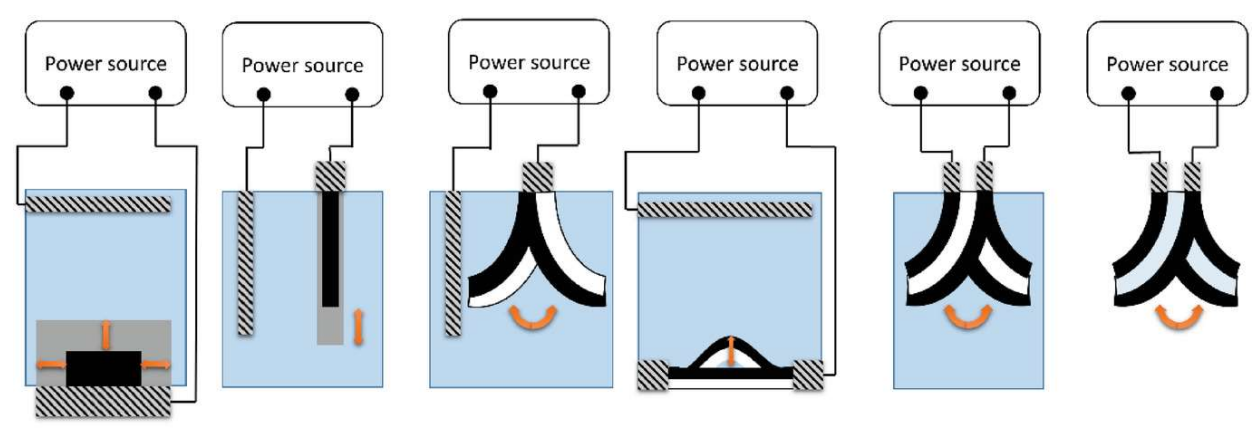

Figure 2.6 Illustration of various conducting polymer actuators with bulk volume change, linear extension, bilayer bending, bilayer buckling sheet, trilayer bending and solid-state trilayer bending (The five actuators to the left operate in the liquid electrolytes and the last one operates in open air). Reprinted with permission from[52]. Copyright (C 2019 WILEY-VCH Verlag GmbH \& Co. KGaA, Weinheim.

\subsubsection{Actuators working in liquid electrolytes}

Since the actuation mechanism of the conducting polymer actuators is activated by an electrochemical redox reaction, a three-electrode electrochemical cell with an aqueous or organic electrolyte is generally required to operate the actuators[53, 54]. The conducting polymer acts as the working electrode where a well-defined electrical stimulation is applied. Inert materials such as platinum, gold, glassy carbon and stainless steel are usually utilized as the counter electrode. A reference electrode is required for regulating the potential of the system and the liquid electrolyte acts as an ion source and provides the required ionic pathways for completing electrical circuits. When potential or current is applied, the electrochemical redox reaction of the working electrode results in reversible volume expansion/contraction of the conducting polymers as discussed previously.

The fundamental form of conducting polymer actuators is the freestanding conducting polymers. These actuators are made by clamping conducting polymer films, strips or fibers at either end. The resulting deformation is a linear actuation of the conducting polymers in liquid electrolyte solution. Direct linear actuation is a simple but important motion mode as complex transmission system is not needed for conversion[52]. These conducting polymer actuators can also offer a direct measurement of actuation metrics such as the expansion and contraction ratio, the generated strain and force, and the response time. Thus, they are particularly useful for understanding the basic performances of conducting polymer actuators. Efforts to improve the performance have been made by optimizing conducting polymer synthesis conditions such as temperatures, applied potentials or choosing a suitable supporting electrolyte solution[55, 56]. However, these linear actuators usually demonstrate considerable electrochemical creep after repeated actuations under stress[57]. The electrochemical creep can be defined as the continuous and irreversible length increase during the actuation process since conducting polymer is also a type of viscoelastic material, while the electrochemical strain is the dynamic 
length variation of the conducting polymer actuator as a result of reversible electrochemical redox process. The electrochemical creep needs to be reduced as it is detrimental for accurate positioning of conducting polymer actuator in the practical use[57]. Another limitation of freestanding conducting polymer actuator is the notable strain gradient especially for long conducting polymer strips when only one end is connected to the electrical source. The applied voltage attenuates longitudinally due to electronic resistance, resulting in the bottom part generating smaller strain and slower speed than its upper section[44, 58].

To provide a uniform current density to the active conducting polymer layer or to strengthen the mechanical properties of the conducting polymer actuators, actuators with bilayer configurations have been designed even though a bending motion is generated[44]. Bilayer actuators usually consist of an active conducting polymer layer and an electromechanically inert layer[59,60]. The relative volume change of the conducting polymer layer with reference to the inert layer results in a bending movement. The inert layers can be a thin metal layer, paper, plastic, or adhesive tape. A bilayer actuator is obtained by the electrodeposition of conducting polymer film directly on a flexible metal substrate or bonding two separately prefabricated layers together.

When two conducting polymer layers are deposited on two sides of a electromechanical inert layer, a trilayer actuator with a typical sandwiched structure is formed[61]. In this case, the working electrode of the potentiostat is connected to one conducting polymer layer and the counter and reference electrodes are connected to the other conducting polymer layer. Opposite electrochemical reactions occur in the two conducting polymer electrodes, with one being oxidized while the other one simultaneously reduced. Consequently, conducting polymer layer on one side expands while the other layer shrinks, generating a bending movement of the trilayer actuator. By reversing the polarity of applied potential, actuators bend in opposite direction. In contrast to other conducting polymer actuators operating in liquid electrolytes, the trilayer actuators are easily controlled with two electrodes since a reference electrode in liquid environment is not required. This trilayer configuration also generates higher output forces than the bilayer configuration due to the presence of two active layers and is more energy efficient as no energy is wasted on the counter electrode. Linear deformation is also achievable in a trilayer configuration if two conducting polymer layers are driven by opposite mechanisms, with one conducting polymer layer driven via a anion mechanism pathway and the other driven via a cation mechanism pathway[62]. Therefore, both conducting polymer layers expand or contract at the same time, producing a linear actuation mode.

\subsubsection{Solid state actuators}

While being able to operate in a liquid electrolyte is advantageous especially for biomedical applications, conducting polymer actuators working in open air would further expand their potential application areas. To achieve solid-state operation, the simple method is to encapsulate the complete device including the liquid electrolyte, which unfortunately leads to a complex structure and may degrade the actuation performance[63]. Another actuator configuration has been developed where the so-called solid polymer electrolytes are used and sandwiched between two conducting polymer electrodes in a trilayer structure[64]. The solid polymer 
electrolyte serves as an ionic source and an electronic insulation layer. Under electrical stimulation, the electrochemical redox process occurs in the same manner as for the trilayers working in the liquid electrolyte, except that the ions are moving between the conducting polymer electrodes and the solid polymer electrolyte. When one conducting polymer electrode is reduced, the second electrode is oxidized. Cations and anions in the central electrolyte layer move separately into different conducting polymer electrode. The relative difference in volume expansion of the two conducting polymer electrodes due to the different ion sizes usually leads to a reversible bending deformation[65-67]. Figure 2.7 illustrates the ion movements in a bending PEDOT:PSS trilayer actuator. The actuation performance of the solid state trilayer actuators are mainly determined by parameters such as the dimensions of the complete structure (length, width and thickness of the conducting polymer electrodes and the solid polymer electrolyte layer), the electroactive actuation properties of the conducting polymer electrodes, ionic conductivities of the solid polymer electrolytes, and the magnitude and frequency of the applied electrical stimulation[68]. The generated force and efficiency of the trilayer actuators is increased as the drag effect in liquid electrolyte is removed and reactions occurring at the counter electrode also contribute to the actuation. Other advantages of the trilayer actuators working in air are that the trilayer actuators are relatively simple to fabricate and they allow easy tuning of the actuation performance, for example, by developing solid polymer electrolyte with proper mechanical, ionic and dimensional properties. However, the solid-state trilayer actuators have some problems in respect of the actuator lifetime. One issue is that the solvent in the solid polymer electrolyte can evaporate especially when an aqueous or organic electrolyte solution is used. The loss of the solvents greatly decreases the ionic conductivity of solid polymer electrolytes and limits the lifetime and performance of the conducting polymer actuators. This evaporation issue can be solved when ionic liquid is utilized as a non-volatile electrolyte[69]. Ionic liquids are molten organic salts with low melting points at ambient temperature. They present large electrochemical windows, high ionic conductivity, have extremely low vapor pressure, and do not require the use of any additional organic solvent. Their use as the electrolyte in conducting polymer actuators results in a significant enhancement in stability, lifetime, and actuation speeds[70-72]. The first demonstration of ionic liquid as electrolytes in conducting polymer actuators is performed by Lu et al. with enhanced cycle number up to 1 million cycles[73]. Therefore, solid polymer electrolyte containing ionic liquid is the ideal materials to develop of high performance solid-state electrochemical actuators. 


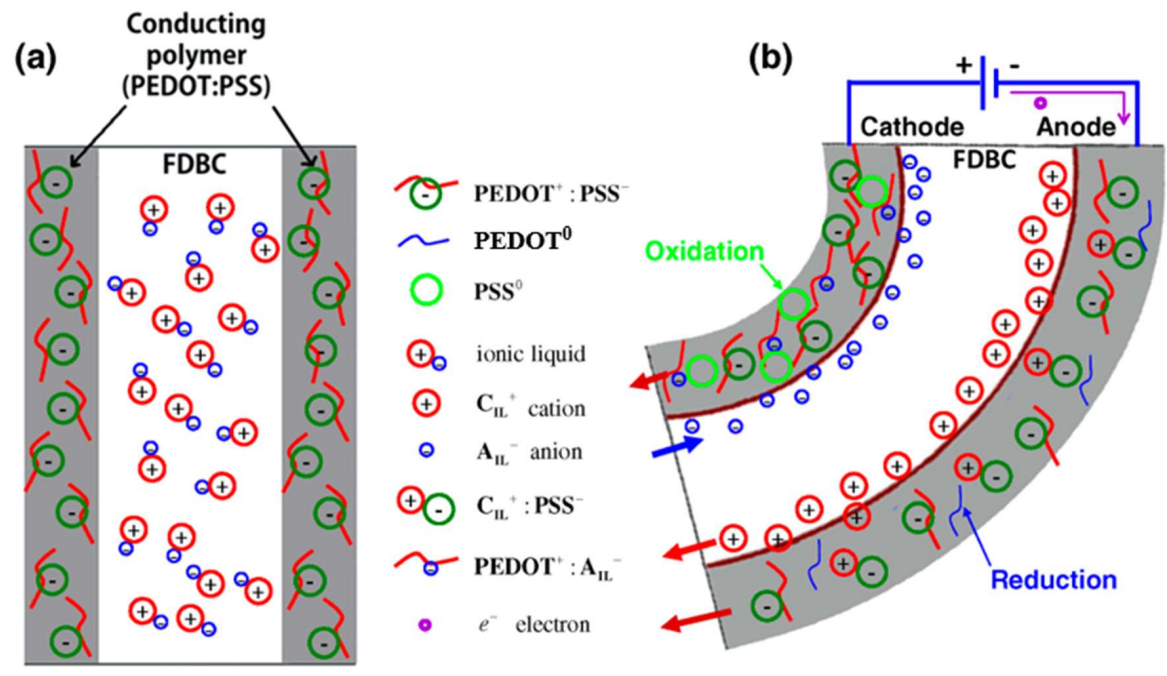

Figure 2.7 Schematic view of the ion movements in a PEDOT:PSS trilayer actuator operating in open air. Reprinted with permission from[65]. Copyright (C) 2013 IOP Publishing Ltd.

The second issue limiting the lifetime is related to the delamination occurring at the interfaces of the layers, due to strong shear forces acting on the central electrolyte layer by the active conducting polymer layers[74]. Various strategies in the design and assembly have been developed to eliminate delamination-associated mechanical failures. Microporous PVdF (polyvinylidene fluoride) polymer membranes are used as the central electrolyte support layer to enhance the physical bonding with the conducting polymer electrodes[72]. Another approach overcoming delamination problem is the synthesis of conducting interpenetrating polymer network (IPN) actuators[66, 75, 76]. In this method, conducting polymer layers are interpenetrated within the polymer electrolyte membrane by chemical oxidative polymerization instead of depositing conducting polymer layer on top of prefabricated electrolyte membrane. The concentration of conducting polymer, which is carefully controlled by the reaction time, decreases from the surface to the central part of the IPN polymer structure without electrical connection occurring between the two penetrated conducting polymer layers. Therefore, solidstate actuators with one-piece pseudo-trilayer configuration are obtained after incorporation of ionic liquid. The typical fabrication process of IPN actuators is illustrated in Figure 2.8[77]. As the conducting polymer layers penetrate the IPN electrolyte layer, no physical delamination can take place during repeated bending[78]. Meanwhile, a novel 3D interface is formed instead of a conventional planar interface between the conducting polymer layers and the central polymer gel electrolyte layer, facilitating the ion exchanges and improving the actuation performance. 

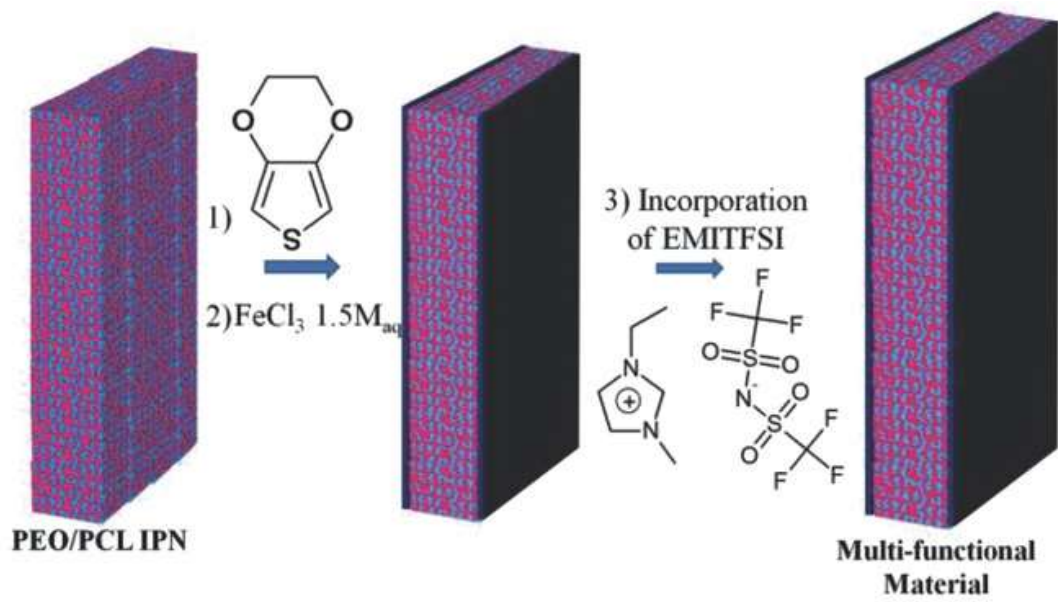

Figure 2.8 Three main fabrication steps for one-piece conducting IPN pseudo-trilayer actuators: 1) impregnating EDOT monomers into PEO/PCL IPN structure, 2) synthesizing interpenetrated PEDOT layer (black layer) within IPN structure using $\mathrm{FeCl}_{3}$ oxidant, 3) incorporating ionic liquid EMITFSI. Reprinted with permission from[77]. Copyright (C) 2015 WILEY-VCH Verlag GmbH \& Co. KGaA, Weinheim.

\subsection{Microactuators}

Over the last decades, there is a tremendous demand for miniaturized actuators for various mechanical, chemical, and biomedical applications[79, 80]. For instance, microactuators operating in biocompatible environments are required to regulate liquid flow as active components in lab-on-a-chip microsystems. Such microactuators should preferably possess a simple structure and should be easily fabricated and integrated into the microsystems. Soft and compliant microactuators are also needed in the applications that require gentle operation such as the micromanipulation and probing of biological samples, micromechanical stimulation of living cells, in-body diagnosis, treatment, and surgery and controlled drug release. However, development in microactuators for such applications is limited because traditional actuation systems such as electromagnetic rotary motors, hydraulic or pneumatic systems are typically nonflexible, heavy, noisy, complex and require significant power to activate the actuation. EAP actuators especially conducting polymer actuators are very promising candidates to fabricate soft microactuators for these potential applications, since they are lightweight, powered at low potentials, move without noise, operate in liquid electrolyte or in open air, and generate large strains and forces. Meanwhile, conducting polymer actuators have a significant drawback that favors its use as microscale actuators. As conducting polymer actuators are ion driven systems, their actuating performance is largely determined by the diffusion rate of ions or accompanying solvents into the conducting polymers[81]. Largescale actuators with thick electrolyte layers and large conducting polymer layers would require too much time for ion transport and are slow 
devices. Substantial improvements in actuation performance are achievable by minimizing ion diffusion distances and reducing actuator dimensions[82]. Therefore, it is of great interest to fabricate high-performance conducting polymer actuators at the microscale. However, miniaturization of conducting polymer actuators and further integration into microsystems is a technical challenge. It must be proved that the soft polymer materials used in conducting polymer actuators are compatible with harsh microfabrication processes, typically developed for silicon-based electronic industry. Different microfabrication techniques or combination of different techniques, including standard photolithography, soft lithography, wet chemical etching, reactive ion etching, inkjet printing, metal deposition and laser ablation, have been used to fabricate conducting polymer based microactuators and their microsystems with a variety of configurations and different purposes[12, 24, 83, 84]. Based on their operation environment, microactuators working in liquid electrolyte solution and in open-air are reviewed separately.

\subsubsection{Microactuators working in liquid electrolytes}

Bilayer microactuators operating in liquid electrolytes are developed by using a few microfabrication steps combining standard photolithography, wet chemical etching and metal evaporation. The first microactuators were developed by Smela et al. in a bilayer configuration of thin gold layer and conducting polymer polypyrrole[85, 86]. These microactuators achieved curling and uncurling movement with a rapid response time of approximately 5 seconds when stimulated in aqueous NaDBS electrolyte solution. This result demonstrates that standard photolithography techniques are compatible with polymer actuating materials and can be used to fabricate thousands of such microactuators in a simultaneous batch-production way. The PPy(DBS) bilayer microactuators are further used as actuating hinges to build more complex microsystems for various applications. For instance, Jager et al. demonstrated a complex design of conducting polymer micro robotic arm, whose joints are driven and controlled by independent PPy(DBS) microactuators. The micro robotic arm can grab and lift a tiny glass bead and position it to another location as shown in Figure 2.9. Such microscale robots from multiple soft conducting polymer microactuators are arguably promising and exciting technology with many possibilities, particularly in biomedical applications because these microactuators demonstrate good biocompatibility and can work in physiological media such as urine, blood plasma, and cell culture media[12]. 

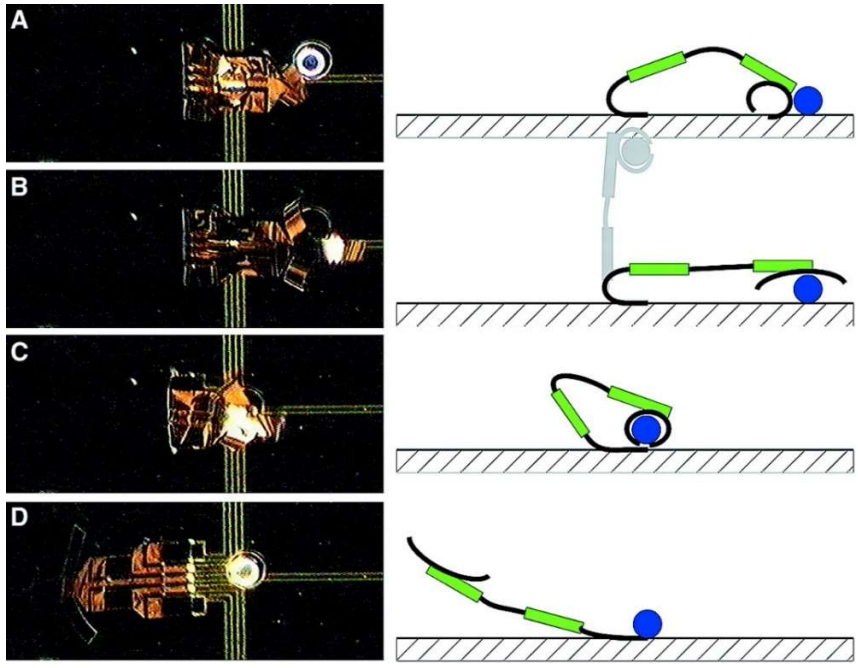

Figure 2.9 Photographs and schematic illustration of a microrobot arm positioning a small glass bead in electrolyte solution. Reprinted with permission from[87]. Copyright (C) 2000 The American Association for the Advancement of Science.

\subsubsection{Microactuators operating in open air}

Solid state trilayer microactuators are also prepared using various micropatterning methods including laser ablation technique, standard photolithography, and reactive ion etching [84, 88]. To downscale the trilayer actuator using laser ablation technique, conventional macroscale trilayer conducting polymer actuator is prefabricated. Microactuators are then simply obtained by laser ablation of the macroscale actuators. For example, microactuators prepared from laser ablation of $\mathrm{Au}$ coated PVdF membrane with two electropolymerized PPy electrodes, demonstrate a fast actuation at $90 \mathrm{~Hz}$ by reducing the dimension of the trilayer actuator and exploiting its fundamental resonance frequency[14, 89]. However, this laser ablation process does not achieve a high resolution, which is largely limited by the laser ablation, nor does it offer batch production. In addition, the obtained microactuators are difficult to connect to the power source due to the lack of integrated electrical contacts.

To achieve even smaller microactuators, a microfabrication process combining spincoating, standard photolithography and reactive ion etching (RIE), is developed for the solid-state trilayer actuators with an IPN structure[13,90]. A layer-by-layer approach is used to prepare large size trilayer actuator on silicon wafer by sequentially stacking three layers together. The layer thickness is precisely controlled by using spin-coating. The synthesized macroscale actuators on silicon wafer are then spincoated with photoresist for photolithographic patterning. Thereafter, the final size and shape of microactuators is determined by the developed photoresist patterns and RIE is used to remove the unprotected materials. The resulting thin microactuators demonstrated actuation at high resonant frequency of $930 \mathrm{~Hz}[13]$. This high- 
definition and cost-effective microfabrication process as illustrated in Figure 2.10 can be easily scaled up at low cost for simultaneous batch-fabrication of fully flexible thin microactuators. However, this RIE method requires manual connection of the microelectrodes for characterization as the absence of both electrical contacts. The process is further improved and allows direct integration of one electrical connection and operation of microactuators on flexible substrates, although an external micromechanical gold tip is still needed to establish the second electrical contact on top of the trilayer [91]. While these fabrication techniques provide the required high resolution for solid-state microactuators and allow for batch fabrication, only simple and individual bending beam microactuators are fabricated.

It is a challenge to create individual addressable monolithic microactuators with fully integrated electric contacts with this method. To build solid state advanced microdevices like microrobots, multiple individually addressable conducting polymer microactuators are needed. This requires development of novel microfabrication methods to pattern conducting polymer actuators. In this thesis, the microfabrication approach created by Smela et al. is modified to fabricate solid state microactuators in a parallel configuration. The two conducting polymer electrodes are positioned parallel in the same plane on a silicon wafer and ionically connected with solid polymer electrolyte micropattern, rather than stacked in a sandwiched trilayer configuration. In other electrochemical devices like electrochromic device and battery, such electrode arrangement is common but not used in conducting polymer electrochemical actuator. To develop the proposed microfabrication process, photopatternable solid polymer electrolyte like a commercial photoresist by traditional photolithography is desired. The use of photopatternable solid polymer electrolytes in the standard photolithography process would broaden the microfabrication toolbox for solid-state microactuators and such a microfabrication method could be easily adapted and extended for other electrochemical microdevices like microsupercapacitors or microbatteries.

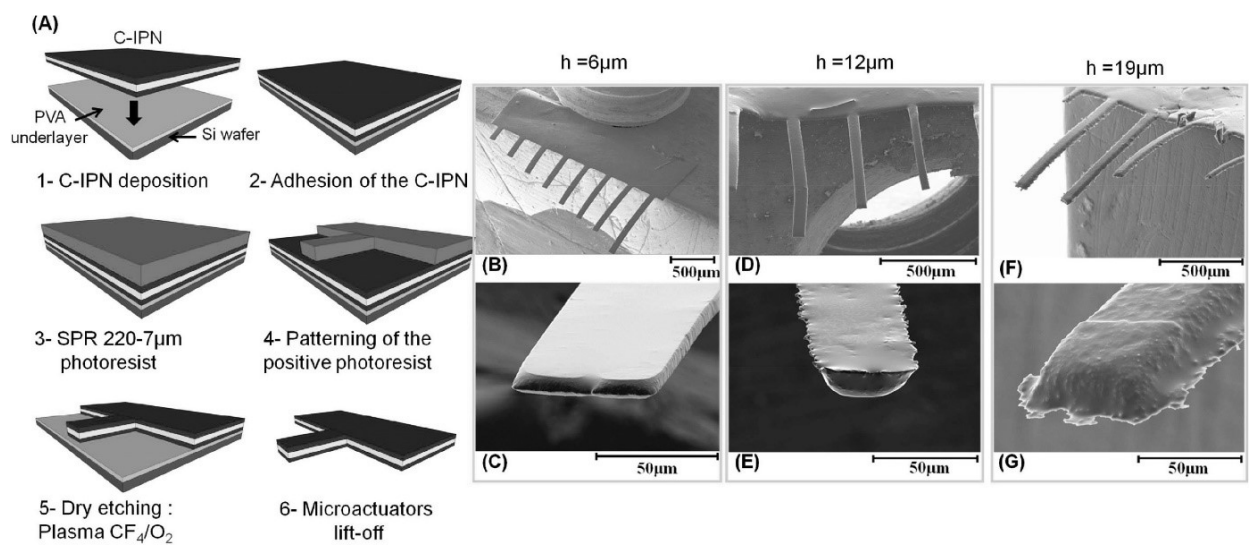

Figure 2.10 Schematic illustration of the microfabrication process combining photolithography and RIE for IPN trilayer microactuators with varying thickness. Reprinted with permission from[13]. Copyright (C) 2014 WILEY-VCH Verlag GmbH \& Co. KGaA, Weinheim. 


\subsection{Advantages and disadvantages of conducting polymer actuators}

There are no perfect actuation materials and technologies. Each has its own advantages and disadvantages and conducting polymer actuators are no exception. Conducting polymer actuators possess some significant strengths over other actuating technologies. They have a relatively simple actuation mechanism. They are lightweight and mechanically soft and flexible. They are noiseless and low in cost. The dimensional change of conducting polymer can be exploited in either linear, volumetric or bending actuators. They are also feasible to fabricate on the microscale and integrated into microsystems. The conducting polymer actuators can work in liquid electrolytes, including some important biological fluids and cell-culture media. They can also operate in air using solid polymer electrolytes in a trilayer configuration. Conducting polymer actuators are electrically controlled, which allows them to be batteryoperated as only a few volts are required. They can be positioned continuously in the strain range and kept at any specified strain without consuming energy[82]. Conducting polymer actuators generate large electrochemical stress at the level of 3-5 $\mathrm{MPa}$, which is significantly higher than that of mammalian skeletal muscles $(0.35 \mathrm{MPa})[92]$. In addition, their electrochemical strain ranges from a few percent to over $30 \%[93,94]$. Some conducting polymer actuators even achieve up to $40 \%$ strain, almost the same level as that of skeletal muscles, even though such extremely large electrochemical strains are obtained using very slow scan rates $[95,96]$. Despite the advantages, there are also some disadvantages associated with conducting polymer actuators. Conducting polymer actuators exhibit notable creep under load, especially for freestanding linear actuators[57]. The evolution of structure of conducting polymers during electrochemical doping and dedoping is hysteretic and only partially reversible, which may gradually reduce the actuating capability of conducting polymer[82]. The conducting polymer actuators respond well at low frequencies as ion diffusion within the materials is a slow process[81]. This severely limits their ability to operate at high frequencies. Thus, they have limited applications especially in cases where large strains and fast response rates are needed at the same time. A typical relationship between displacement and frequency for conducting polymer bending actuators is shown in Figure 2.11. Another weakness of conducting polymer actuators is that the efficiency of energy transformation from electrical to mechanical form is usually low at the level of $1 \%$ or less[82]. This problem rules out the applications of conducting polymer actuators as macroscale devices such as prosthetics even when high speed actuation is not needed, unless the energy efficiency can be enhanced[97]. Therefore, it is challenging and not reasonable to replace or compete with other existing actuation technologies in applications that are unsuitable for conducting polymer actuators. Identifying a critical need for conducting polymer actuators in a niche application is significantly beneficial to their development. Continuous development of high-performance conducting polymers, electrolyte materials, novel fabrication techniques and smart design of actuator configurations can be used to lift their current limitations and broaden their future applications. 


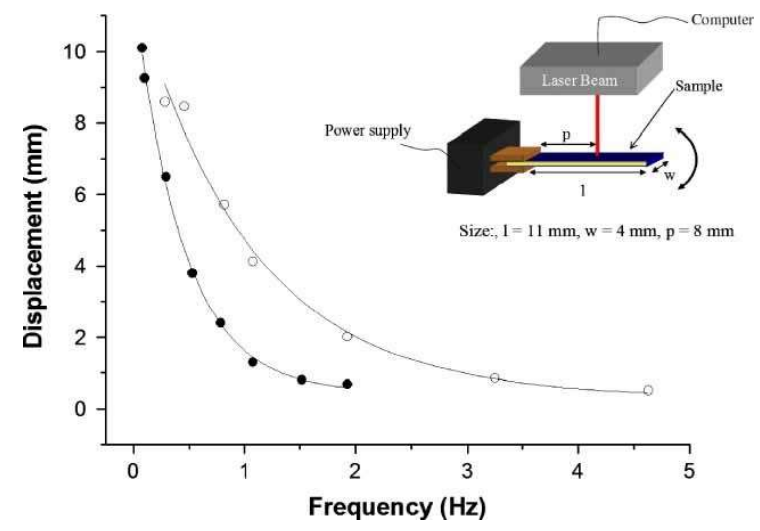

Figure 2.11 A typical relationship between displacement and frequency for trilayer bending actuators. The displacement decreases with increasing frequency. The filled and open circles indicate two different actuators. Reprinted with permission from[98]. Copyright (C) 2010 Society of Chemical Industry. 


\section{Chapter 3 Thiol-ene chemistry}

\section{1 "Click" chemistry}

"Click" chemistry is a novel concept for efficient and selective chemical reactions proposed by Kolb, Finn, and Sharpless for the first time in 2001[99, 100]. The click reactions exhibit some exceptional characteristics including: a) simple, efficient, and modular in nature; b) nearly ideal 1:1 stoichiometry; c) high yields with by-products that need simple or no purification; d) regiospecific and stereospecific; e) simple to practice in mild reaction conditions and tolerant of water and oxygen; f) orthogonal to chemical substrates and g) amenable to readily available reaction substrates. A few chemical reactions such as $\mathrm{Cu}$-catalysed azide-alkyne cycloaddition (CuAAC), hetero Diels-Alder reaction, nucleophilic ring-opening reactions of strained heterocycles, thiol based free radical or Michael addition reaction, have been identified as click reactions under appropriate conditions[101, 102]. During the past decades, the "click" chemistry has demonstrated its significance in a wide variety of applications such as organic synthesis, surface functionalization, molecular biology, biotechnology, bioconjugation, polymer synthesis and modification, polymer network formation, and dendrimer synthesis[103$106]$.

\subsection{Thiol-click reactions}

This thesis is focused on thiol-based click reactions. Thiol groups in these reactions typically exhibit high reactivity as the relatively weak sulphur-hydrogen bonds can break into highly reactive species including electrophilic thiyl free radical and nucleophilic thiolate anion[107]. These two reactive species can readily react with many chemical substrates including enes, alkynes, halogens, epoxies, and isocyanates. These thiol reactions possess many characteristic features of the click reactions. Specifically, they are fast, produce high yields under relatively benign conditions, proceed either without or in common solvents, and usually generate one product so that either no or simple purification is required. Thus, the click reaction nomenclature is adapted in the literature to refer these different thiol based click reactions[108]. A literal reaction toolbox of various thiol-based click reactions is shown in Scheme 3.1. However, these thiol-click reactions also have some inherent drawbacks in contrast to other efficient click reactions. For example, the high reactivity and efficiency of thiol groups as they can react with many chemical substrates under mild conditions also means their orthogonality is compromised, which makes them susceptible to participate multiple reactions simultaneously when mixed substrates are present. Other downsides of the thiol based click reactions include low shelf stability for some formulations and unpleasant odour and toxicity especially for low molecular weight thiols[109, 110]. 


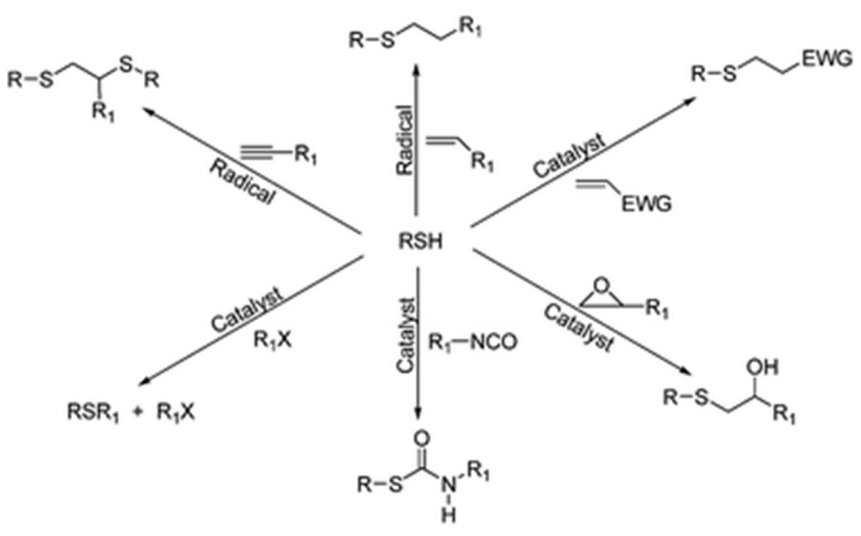

Scheme 3.1 Schematic illustration of various efficient thiol-based click reactions. Reprinted with permission from[108]. Copyright (C) 2010 The Royal Society of Chemistry.

\subsection{Thiol-ene coupling chemistry}

This chapter is mainly focused on thiol-ene coupling reaction, which represents the reactions of thiol groups with many unsaturated chemical groups including maleimides, allyl ether, vinyl ether, acrylates, methacrylate, vinyl sulfone and norbornenes. Generally, thiol-ene coupling chemistry can be grouped into two categories: radical assisted thiol addition or catalyst mediated thiol Michael addition to carbon-carbon double bond (Scheme 3.2). The same thioether product is produced between thiol and ene in both reactions under ideal conditions.

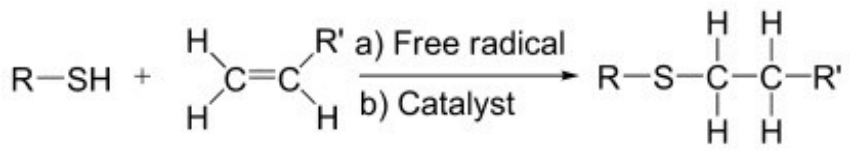

Scheme 3.2 Idealized representation of free radical (a) and catalyst mediated (b) thiol-ene coupling chemistry. Reprinted with permission from[107]. Copyright C 2010 WILEY-VCH Verlag GmbH \& Co. KGaA, Weinheim.

\subsubsection{Ideal free radical thiol-ene coupling reaction}

The free radical thiol-ene addition reaction generally proceeds in three main steps: initiation, propagation and termination. The initiation step starts from the reaction of thiols with free radicals generated from initiators or direct UV illumination, producing reactive thiyl radicals 
$(\mathrm{R}-\mathrm{S} \cdot)[111]$. In the following propagation step, the thiyl radical is directly added across the carbon-carbon double bond creating an intermediate radical. This carbon-centered radical removes a hydrogen radical from other thiol group to form the thiol-ene addition product, simultaneously creating a new initiating thiyl radical. The free radical reaction is terminated by classic radical/radical coupling processes. As a result, the thiol-ene free radical coupling reaction is simply the addition of thiol to ene in a step growth mechanism while having all the advantages of a rapid radical initiated reaction at the same time. When allyl ether, vinyl ether, or norbornenes are used as ene substrates, the thiol-ene free radical reactions are ideal without homopolymerization of enes (Scheme 3.3). In such ideal conditions, the thiol-ene free radical polymerization exhibits a simple reaction kinetics and the reaction rates of propagation and chain transfer steps are essentially identical. High conversion of functional groups is achievable unless they are prevented by mass-transfer limitations.

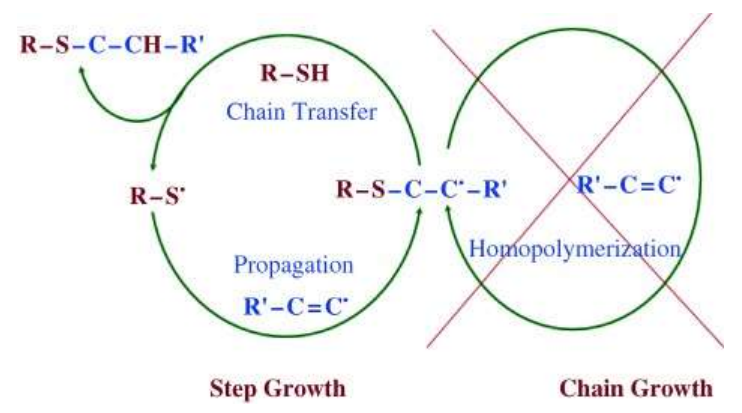

Scheme 3.3 Ideal reaction mechanism with alternating propagation and chain transfer steps in thiol-ene free radical coupling reaction. Reprinted with permission from[107]. Copyright $(C)$ 2010 WILEY-VCH Verlag GmbH \& Co. KGaA, Weinheim.

\subsubsection{Thiol (meth)acrylate free radical mixed mode reaction}

When the homopolymerizable enes such as (meth)acrylates are used as the reaction substrates, the thiol-ene free radical reaction takes place through a mixed mode mechanism containing two different reaction cycles (Scheme 3.4)[112, 113]. The first cycle involves alternation of chain transfer and propagation in a step growth fashion, and conventional free radical polymerization proceeds via chain growth mechanism in the second cycle. The relative rates of these two cycles depend on chemical structures, concentrations and reactivities of the thiol and (meth)acrylate components. This mixed mode reaction has a relatively complex kinetic, but the presence of the thiol offers several significant benefits that are not obtainable with conventional (meth)acrylate homopolymerization. First, a small quantity of thiol materials at the level of 1$10 \mathrm{wt} \%$, is able to greatly mitigate oxygen inhibition problem, even when the polymerizing films are only several micrometers thick and exposed to ambient air[114]. The reduced oxygen inhibition increases the polymerization rate and a high conversion of functional groups especially on the surface is achievable. Secondly, the presence of step-growth addition mechanism allows a delayed gel point and reduced shrinkage stress that arises during the 
polymerization process[115]. Furthermore, a certain number of excess thiol groups remains after the completion of the reaction as (meth)acrylates participate in both reaction cycles and homopolymerization of (meth)acrylates is faster than thiol (meth)acrylates free radical addition reaction[116]. These remaining thiol chemical groups may provide a distinctive opportunity to modify polymer materials, which are impossible by classical free radical polymerization or ideal thiol-ene free radical polymerization techniques.

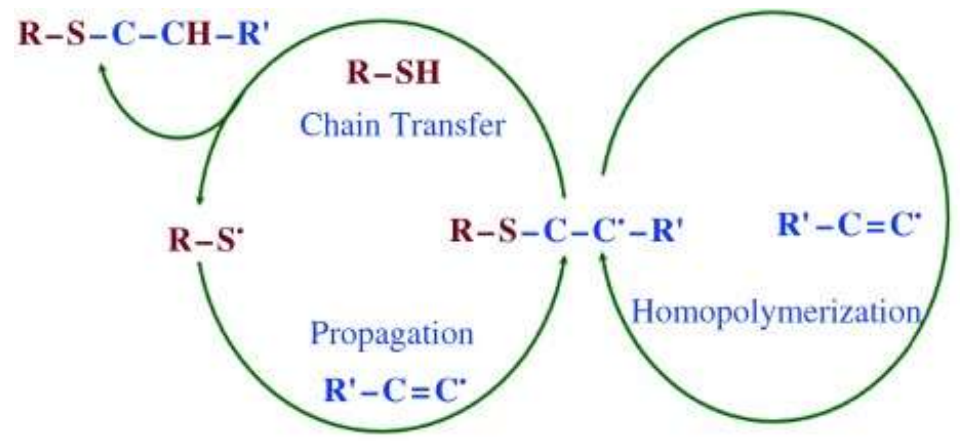

Step Growth

Chain Growth

Scheme 3.4 Reaction mechanism of thiol (meth)acrylate free radical mixed mode polymerization. Reprinted with permission from[107]. Copyright (C) 2010 WILEY-VCH Verlag GmbH \& Co. KGaA, Weinheim.

\subsubsection{Catalyst mediated thiol-ene Michael addition}

Besides the common free radical pathway, thiol groups also readily react with electron-poor enes with a catalyst in thiol-ene Michael addition reactions to produce a thioether product[117, 118]. The reactions proceed at room temperature in an extremely efficient and quantitative anionic step growth coupling process. The reaction has a similar mechanism as in the ideal thiol-ene free radical addition reaction, except that free radicals are replaced with reactive anions for initiation and there are no anionic termination processes. A wide variety of efficient catalysts including hexylamine, triethylamine, dimethyl phenyl phosphine, and triphenyl phosphine are utilized in the thiol-ene Michael addition chemistry[119]. Based on different initiating mechanisms, these catalysts are divided into two main groups, base and nucleophile.

\subsubsection{Base catalyzed thiol-ene Michael addition}

In the base catalyzed reaction, catalytic amounts of a base are needed to accelerate the thiol-ene Michael addition reaction between thiol groups and electron deficient ene groups[120, 121]. 
The most used base catalysts are amine based catalysts such as triethylamine[117]. The generally accepted reaction mechanism is given in Scheme 3.5. A proton in the thiol group is removed by the base catalyst to produce a reactive thiolate anion (RS-) and a conjugated acid. The generated thiolate anion is very nucleophilic and then it reacts with the electron poor ene group, producing a highly reactive carbon-centred intermediate anion. As a strong base material, the generated anion removes a proton in the conjugated acid, producing the thioether group as the final thiol-ene Michael addition product and regenerating the base catalyst concomitantly. Overall, all thiol and electron deficient ene groups are covalently connected with a thioether bond after these reaction steps, usually at near quantitative conversion.

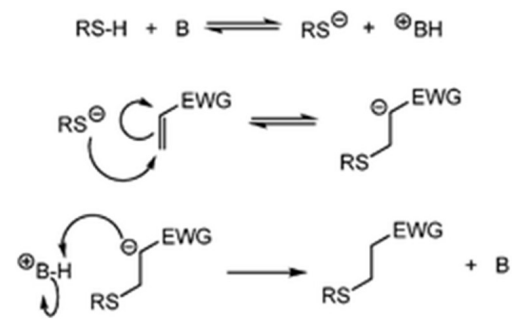

Scheme 3.5 The mechanism of base catalyzed thiol-ene Michael addition reaction. Reprinted with permission from[108]. Copyright (C) 2010 The Royal Society of Chemistry.

\subsubsection{Nucleophile catalyzed thiol-ene Michael addition}

Nucleophiles are emerging as an extremely efficient class of catalysts for thiols and electrondeficient enes in thiol-ene Michael addition reactions[119, 120,122]. These catalysts including primary amines, secondary amines, and phosphorus-centered catalysts act as a nucleophile in another pathway different from base catalyzed reaction (Scheme 3.6). The electron poor carboncarbon double bond is initially attacked by the nucleophilic catalyst to generate a strong intermediate zwitterionic carbanion, which removes a proton from thiol group and generates an initiating thiolate anion. The resulting thiolate anion initiates the subsequent thiolene Michael addition reaction and ensures rapid reaction kinetics. Both the nucleophile and base catalyzed thiol-ene Michael reactions can be characterized as highly efficient click reactions under appropriate conditions because of rapid reaction rates, regiospecificity, insensitive to air and moisture, high selective product, quantitative yields, and mild reaction conditions. The presence of proton sources like alcohol or water has no effect on the reaction in sharp contrast to other anionic polymerization processes. However, these two mechanisms result in some differences in their reaction attributes[123]. The nucleophilic Michael addition reaction generally achieves higher functional group conversions with relatively low catalyst concentrations and is less dependent on the $\mathrm{pKa}$ of the thiol used, while it is an important factor that affects the reaction kinetics in thiol-ene Michael reactions mediated by base catalysts. It should be noted that both the nucleophile and the base catalyzed reactions are strongly affected by external acidic materials if presented in the reaction. The base catalyzed reaction pathway is 
less influenced as the needed concentrations of the base catalyst is much higher than that in a typical nucleophilic pathway. In an extreme case, the thiol-ene Michael reaction is completely inhibited by the presence of external protic materials such as a strong acid, which can be considered a disadvantage of this reaction[118].

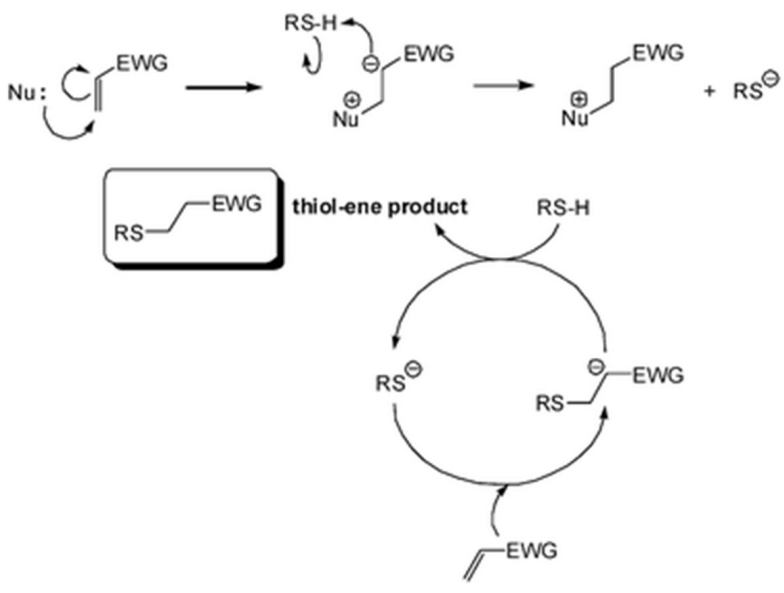

Scheme 3.6 The nucleophilic mechanism of thiol-ene Michael addition reaction. Reprinted with permission from[108]. Copyright (C) 2010 Royal Society of Chemistry.

\subsection{Monomers used in thiol-ene coupling reaction}

The overall reaction rate, conversion, and kinetics of thiol-ene Michael addition reactions are dependent on many parameters such as catalytic mechanism, catalyst concentration, the basicity or nucleophilicity of the catalyst, $\mathrm{pKa}$ and steric effect of the thiols, and electron-withdrawing group on the unsaturated carbon-carbon double bond $[119,124]$. Other factors like the polarity and the $\mathrm{pH}$ of the solvent also influence the reaction kinetics in the case of reactions in solution[125, 126]. Common monomers used in the thiol-ene coupling chemistry and their reactivities are discussed below.

\subsubsection{Thiol monomers}

The most outstanding feature of either radical assisted or catalyst mediated thiol-ene addition chemistry is that almost any type of thiol can be employed[127]. However, the reactivity of thiols ranging several orders of magnitude, is dependent on the structure of the thiol groups as the strength of sulphur-hydrogen bond in various thiol group differs and cleaves via a homolytic 
or heterolytic mechanism. Four common types of thiol structures including alkyl thiols, thiol propionates, thiol glycolates and thiophenols, have been investigated in the literature to reveal the effect of the chemical structures on the reactivity of the thiol (Figure 3.1). As indicated by the arrows, thiols with high $\mathrm{pKa}$ result in corresponding thiolate anions with high nucleophilicity, which favours thiol-ene Michael addition reaction, while thiols with low pKa lead to radicals with high electrophilicity, which favours free radical mediated thiol-ene coupling reaction.
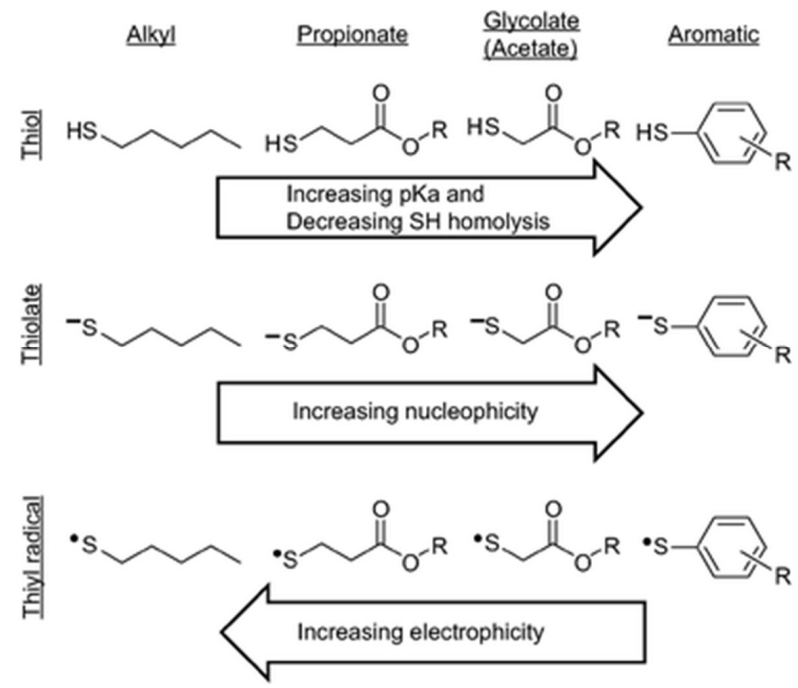

Figure 3.1 Structures and reactivity of four common thiols and their corresponding thiolates and thiyl radicals. Reprinted with permission from[108]. Copyright (C) 2010 Royal Society of Chemistry.

\subsubsection{Ene monomers}

A wide variety of enes can be used as suitable substrates in thiol-ene free radical coupling chemistry, including activated and non-activated carbon-carbon double bonds. The reactivity of the ene monomers differs significantly with various structures and substitution groups of the ene monomers. The overall reaction kinetics of the thiol-ene free radical reaction is influenced by the electron density on the carbon-carbon double bonds. Initiating thiyl radicals react with electron-rich enes more rapidly than electron deficient enes. The relative reactivity of enes towards thiols under free radical reaction conditions follows a general trend: "norbornene $>$ vinylether $>$ propenyl $>$ alkene $\approx$ vinylester $>$ N-vinylamide $>$ allylether $\approx$ allyltriazine $\approx$ allylisocyanurate $>$ acrylate $>\mathrm{N}$-substituted maleimide $>$ acrylonitrile $\approx$ methacrylate $>$ styrene $>$ conjugated diene" $[128,129]$. The reactivity of ene monomers increases with increasing electron density on the carbon-carbon double bond excluding three special enes: norbornene, 
methacrylate, styrene, and conjugated dienes. The attack of the initiating thiyl radical on the carbon-carbon double bond in norbornenes significantly releases the strain of the heterocyclic ring and the subsequent generated carbon-centered radical has a high hydrogen-abstraction rate from the thiol group. These combinational effects are attributed to the exceptionally high reactivity of strained norbornenes. While methacrylates, styrenes and conjugated dienes have a low reactivity because of the high stability and inherently low hydrogen abstraction rate of their intermediate carbon-cantered radicals. The position of the double bonds in molecular structure also influences the reactivity with terminal enes significantly more reactive than internal enes. The structure of the ene monomers also strongly affects the reaction kinetic in the thiol-ene Michael addition reaction. Generally, electron-poor enes is more susceptible to a Michael addition reaction. Common electron-deficient enes used in thiol-ene Michael addition reactions are acrylamides, acrylates, vinyl sulfones, methacrylates, and maleimides. Their relative reactivity in thiol-ene Michael addition reaction is shown in Scheme 3.7[119].

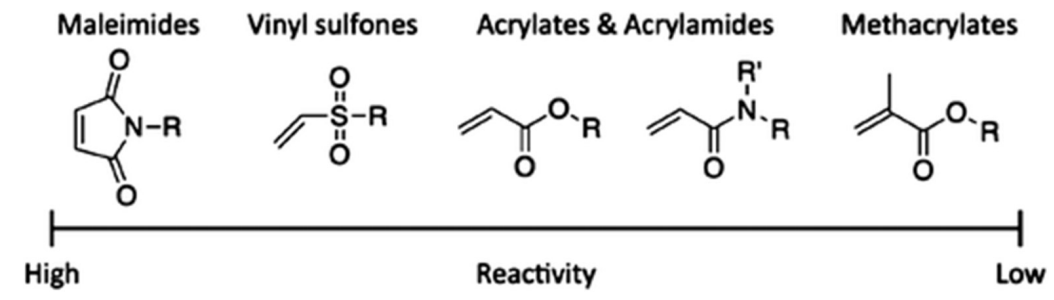

Scheme 3.7 Structures and relative reactivity of commonly used enes in thiol Michael addition reactions. Reprinted from permission from[123]. Copyright (C) 2014 American Chemical Society.

\subsection{Oxygen inhibition}

Conventional free radical chain growth polymerization reactions suffer several serious problems such as substantial volume shrinkage and stress, complex polymerization kinetics, and highly heterogeneous polymer network formation. Another significant drawback of conventional free-radical polymerization process is oxygen inhibition[130]. In an oxygen-rich environment, propagating radicals can transform into peroxy radicals by reacting with oxygen molecules. These peroxy radicals are unreactive and lose the capability to initiate acrylate polymerization, thus the overall conversion of acrylates in air is severely limited, resulting in an uncured and tacky surface in most cases. In order to reduce the oxygen inhibition, acrylatebased materials are frequently polymerized with the need of a controlled inert atmosphere, oxygen degassing process, or high initiator concentration, which limits their application in photopatterning process. However, oxygen inhibition is significantly reduced in the free-radical thiol-ene coupling reaction as the inactive peroxy radical removes a hydrogen from the thiol, creating a reactive thiyl radical that can reinitiate the reaction with little or no compromise in the reaction kinetics (Scheme 3.8)[114]. The oxygen that diffuses into the thiol-ene radical polymerizing system is depleted by the thiols and a high conversion of acrylates is obtained 
even on the surface. This strategy is used to reduce the oxygen inhibition in acrylate free radical polymerizations by incorporating thiols into the acrylate formulation. A relatively small quantity of thiols can significantly mitigate oxygen inhibition issue and accelerate the polymerization rate, even in thin films with a few micrometers thickness, which is quite advantageous for curing thin films and coatings in air.

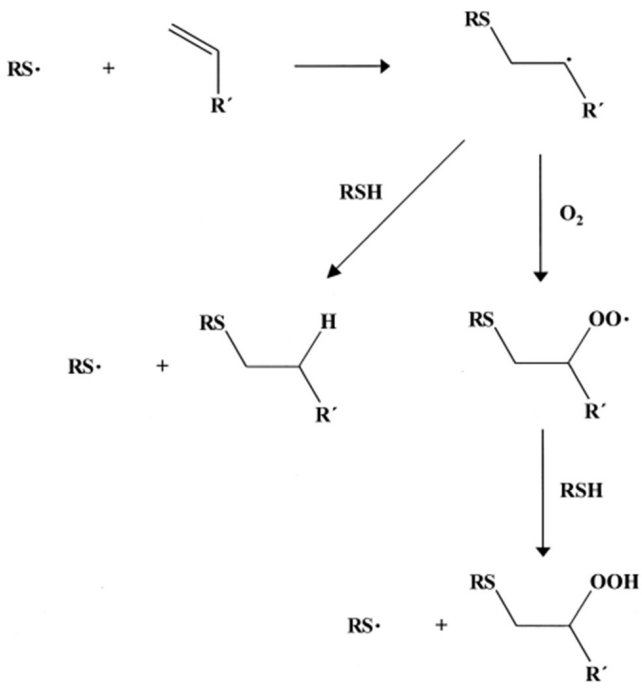

Scheme 3.8 The mechanism of reduced oxygen inhibition in thiol incorporated free radical reaction. Reprinted from permission from[128]. Copyright (C) 2004 Wiley Periodicals, Inc.

\subsection{Properties of thiol-ene based polymer networks}

Crosslinked polymer network system employing radical or catalyst mediated thiol-ene coupling reaction offers several distinctive polymerization characteristics and exceptional polymer network properties that are impossible with traditional free radical chain-growth polymerization systems. These interesting attributes include significantly simplified and rapid polymerization kinetics and insensitivity to oxygen inhibition, which results in rapid production of crosslinked polymer networks in air. Considerable stress in polymer network is accumulated during the free radical chain-growth polymerization such as acrylates as gelation occurs at low conversions of monomers, while the delayed gelation from thiol-ene step-growth polymerization significantly reduces the polymerization-induced shrinkage and stress. This is because large part of the whole polymerization process occurs before the gel point in a low-molecular-weight, viscous liquid status. Thiol-ene based polymer network features an inherent stability resulting from the 
flexible thioether group, which acts as a well-known antioxidant[128]. Some thiol-ene networks show that glass transition temperature does not change during aging for up to one month, indicating a good thermal and anti-oxidative stability. Thiol-ene based polymer networks possess another important advantage over traditional networks because their crosslink density can be controlled precisely, and thus nearly perfect and uniform polymer network is produced while polymer network by conventional free radical polymerization reactions is inherently heterogeneous. The exceptional network uniformity imparts their rather narrow glass transition temperature region and enhanced mechanical properties. This also suggests that incorporating multifunctional thiols into the free radical acrylates polymerizing system can improve the physical and mechanical behaviors of the resulting polymer networks. The network formed in such thiol-acrylate formulations proceeds via a mixed polymerization process combining acrylate polymerization and thiol-acrylate step-growth coupling reaction instead of a pure acrylate homopolymerization. As a result of thiol-acrylate step growth mechanism, a much more uniform polymer network is formed, even when a small amount of thiol is added to acrylates.

\subsection{Light induced thiol-ene coupling reaction}

Using light to initiate thiol-ene coupling reactions has enormous advantages, including rapid polymerization kinetics, low reaction temperature (often at room temperature), low energy required, temporal and spatial regulation of the initiation, and facile manipulation of the reaction rate and conversion rate by directly controlling the illumination intensity, the dose or the exposure time. Light induced thiol-ene coupling reactions possess a combination of the traditional advantages of thiol-based click reactions with the benefits of a photoinduced reaction, resulting in an important synthesis technique for a wide variety of applications in polymer and materials science like photopatterning, polymer modification, bioconjugation, surface immobilization, and biochemical labelling. The thiol-ene coupling reaction initiated by free radicals can be triggered conveniently with UV light through a wide selection of free radical photoinitiation systems. However, such photoinitiation systems are limited for thiol-ene Michael addition reactions compared to radical photoinitiation as they are generally initiated utilizing base or nucleophile catalysts. To realize light induced thiol-ene Michael addition reactions, a few photocatalyzing systems have been designed in the past few years[131-133]. The most straightforward method to trigger the reaction by photo-illumination is to design photolabile molecules that release bases or nucleophiles. These photoinitiation catalysts are synthesized by linking light sensitive functional group to a strong base, such as tetramethyl guanidine. Typical light sensitive functional groups, like tetraphenylborate, nitrophenyl propyl, phenylglyoxylic acid, and coumarin derivative, are used. As an example, a highly reactive catalyst prepared through protecting tetramethyl guanidine (a strong base) with a visible light sensitive coumarin derivative group is shown in Scheme 3.9. The catalyst exhibits excellent catalytic activities toward the initiation of the thiol-ene Michael addition reaction and high conversion of vinyl functional groups is reached within several minutes for homogeneous network formation. 


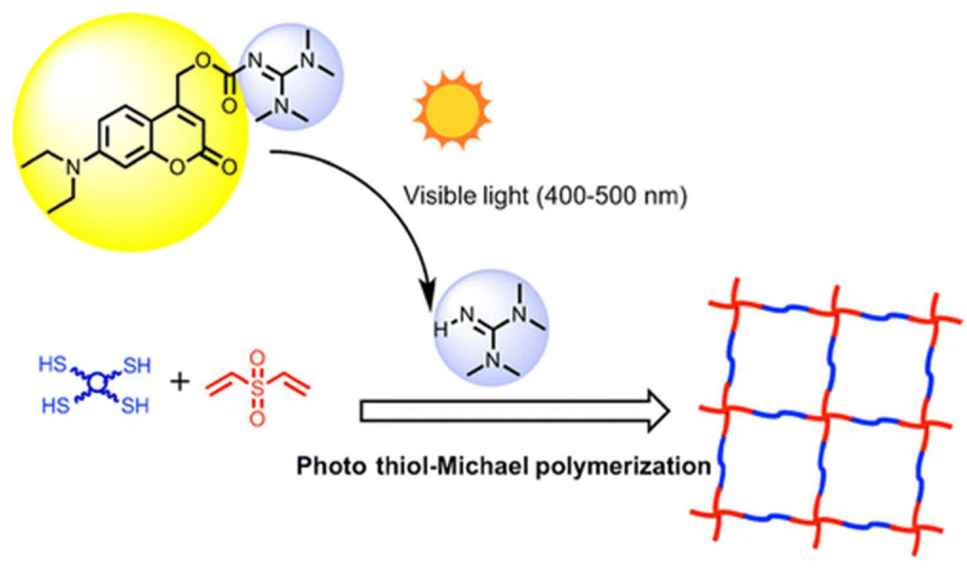

Polymer Network

Scheme 3.9 A visible-light photoinitiation system for homogeneous network formation by thiol-ene Michael reaction. Reprinted with permission from[134]. Copyright (C) 2016 American Chemical Society.

\subsection{Application of thiol-ene coupling reaction in patterning}

Thiol-ene coupling reaction has a significant potential for the development of complex micro/nano polymer-based patterns and structures, which have been explored by various patterning techniques including classic photolithography, electron beam lithography, reaction injection molding and soft lithography[135-138].

\subsubsection{Photolithography}

Photolithography is a traditional micro/nano-fabrication process to transfer geometric patterns from a photomask to a flat substrate with the help of light sensitive polymers (called photoresist). It allows a precise control of the shape and size of the patterns and enables the creation of micro/nano patterns in a highly mass-production manner. To begin the photolithographic process, the photoresist is initially applied evenly on the substrate by a spin coating method. Controlled light exposure through a photomask is performed to define the area where the light interacts with the photoresist layer. The interaction creates a difference in solubility of the photoresist between exposed and unexposed areas in the developer solution. Appropriate solvents are used to remove the soluble materials during the subsequent development process. The patterns on the photomask at this point have been transferred to the photoresist layer. A further etching step is then performed to transfer the patterns into the underlying layer. There are two groups of photoresists developed for photolithography: positive photoresist or negative 
photoresist. For positive photoresist, the illumination of the light changes the chemical structure in the positive photoresist so that it becomes more soluble in the developer. An exact copy of the pattern on the photomask is transferred to the positive photoresist layer. For negative photoresist, the exposure of light initiates polymerization or crosslinking reactions so that the exposed photoresists are difficult to dissolve in developer. The patterns on the photomask is inversely transferred to the negative photoresist layer. Figure 3.2 compares the patterning results using these two types of photoresists in a photolithographic process. The step-growth mechanism in the thiol-ene coupling chemistry and the associated delayed gelation, rapid reaction kinetics, uniform polymer network, negligible oxygen inhibition, and low shrinkage stress, make this thiol-ene reaction suitable to develop negative-toned photoresist materials in the photolithographic patterning process[138-140]. The delayed gelation and low shrinkage stress lead to sharp photolithographic profiles, which possess a well-defined and distinct boundary between exposed and unexposed photoresist regions. The absence of oxygen inhibition issue and rapid reaction kinetics leads to complete curing of thin photoresist layer in air without a controlled nitrogen atmosphere, improving the achievable resolution in lithographic applications.

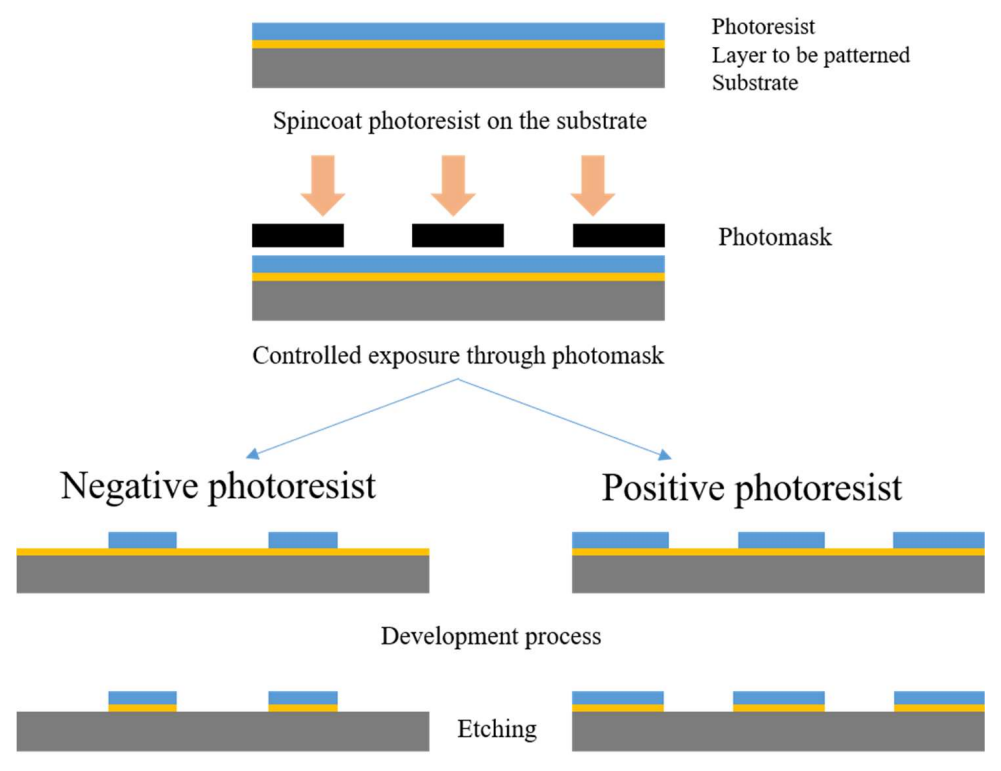

Figure 3.2 Schematic illustration of photolithographic patterning process using either negative or positive photoresist. 


\subsubsection{Soft lithography}

Soft lithography is viewed as an alternative to photolithography and contains a family of patterning techniques designed for fabricating or replicating patterns and structures using soft elastomeric stamps or molds, which are usually made from polydimethylsiloxane (PDMS)[141]. These techniques include a wide range of processes, like microcontact printing method $(\mu \mathrm{CP})$, micromolding in capillaries (MIMIC) or replica molding. The application of thiol-ene reaction in soft lithography patterning methods is discussed using microcontact printing method as an example. In $\mu \mathrm{CP}$ patterning process, a PDMS stamp with designed patterns is coated with a thin layer of ink molecules and placed on a reactive substrate under a certain force. The ink molecules on the stamps react only in the contact area and functional micropatterns are acheived in a single and rapid printing procedure. Significant benefits of microcontact printing are that reactions proceed very rapidly, and only small quantities of ink molecules are needed in the patterning process, which is particularly useful for patterning of biological molecules like carbohydrates, nucleic acids or proteins because these materials are usually available only in small quantities. $\mu \mathrm{CP}$ process creates high resolution patterns, which are not influenced by the optical properties of the substrate, while reflection and scattering of light on substrates affect the resolution of photolithographic patterns. Several favorable properties of thiol-ene reactions, like the absence of oxygen inhibition, fast kinetics, high conversion rate, and their ability to self-initiate without extra added initiators, make them attractive in micro/nano contact printing application. A typical photochemical $\mu \mathrm{CP}$ process using thiol-ene coupling chemistry is illustrated in Figure 3.3 for the patterning of functional thiols on the substrate covered with alkene-terminated self-assembled monolayers[137]. The PDMS stamp is covered with a layer of functional thiols (illustrated in red). After bringing the stamp in contact with the substrate, a thiol-ene reaction is initiated in the local contact area by irradiation with UV light. A wide range of functional thiols are conveniently patterned and immobilized on the substrate within $30 \mathrm{~s}$ of printing and the edge resolution of the micropatterns is better than $100 \mathrm{~nm}$. Therefore, photochemical $\mu \mathrm{CP}$ coupled with thiol-ene chemistry is a valuable alternative to photolithography and is advantageous for the preparation of micropatterns for biological materials.

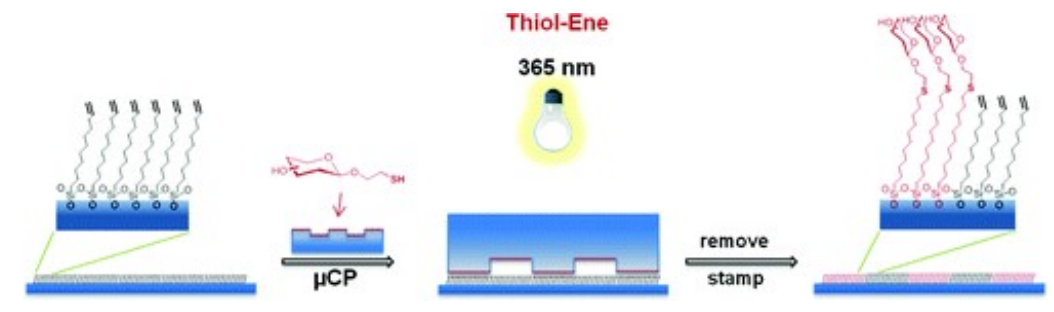

Figure 3.3 Schematic illustration of thiol-ene photochemistry for micro contact printing application. Reprinted with permission from[137]. Copyright (C 2010 American Chemical Society. 


\subsection{Thiol-ene based polymers for fabrication of microfluidic devices}

The thiol-ene based photopolymers have also proven useful to fabricate microfluidic devices, which are traditionally fabricated from hydrophobic poly(dimethylsiloxane) (PDMS) by soft lithography techniques[142, 143]. The exceptional thiol-ene reaction allows to fabricate microfluidic devices with many highly desirable features. Reduced or complete absence of oxygen inhibition in thiol-ene reactions decreases the photoinitiator concentration, while fast reaction kinetics and excellent surface curing are still achievable. Reduced photoinitiator concentration is beneficial for light penetration, allowing for the fabrication of thick and uniform polymerized features for microfluidic components. Delayed gelation and reduced shrinkage stress are also important features of thiol-ene polymer network, which remains in the liquid state in the network evolution until relatively high conversion is reached because of the involved step-growth mechanism. These combined advantages of thiol-ene photopolymers facilitate the production of structures with large aspect ratio and high fidelity. Thiol-ene coupling chemistry also allows easy control of the surface properties of microfluidic parts for the assembly of microfluidic devices[144, 145]. Off-stoichiometric thiol-ene (OSTE) photopolymers are developed to fabricate two thiol-ene photopolymers with different surface properties. The microfluidic parts are fabricated via soft lithography techniques from the offstoichiometric thiol-ene photopolymers and the assembly of microfluidic device is achieved with one single-step UV induced click reaction between the excess thiols and allyl groups on the surface. These novel thiol-ene materials provide a facile fabrication method for hydrophilic microfluidic chips with enhanced interfacial stability and resistance to solvent, in contrast to PDMS based microfluidic devices.

\subsection{Thiol-ene photopolymers for 3D printing}

The polymer 3D printing technology has received a huge amount of attention in various applications because of its excellent process flexibility and geometry controllability[146]. The characteristics of the thiol-ene reaction makes it an interesting candidate for photopolymerizable system to be investigated for 3D printing[147]. Thiol-ene based photopolymers demonstrate less volume contraction and shrinkage stress during polymerization in sharp contrast to acrylate-based free radical formulations and as a result the printed objects present a sharp and smooth surface. The capability to cure thiol-ene photopolymers in the openair is also favorable as the curing process in open vat stereolithography setups occurs in the presence of ambient air. 3D printing of thermoplastic polymer in open-air at high speed is achieved with a thiol-incorporated printing formulation[148]. A thiol-ene free radical photopolymer developed for 3D printing system is shown in Figure 3.4[149]. A high-resolution dog structure of $50 \mu \mathrm{m}$ is easily created with digital light processing (DLP) printing from the thiol ene formulation using a visible LED light source. 


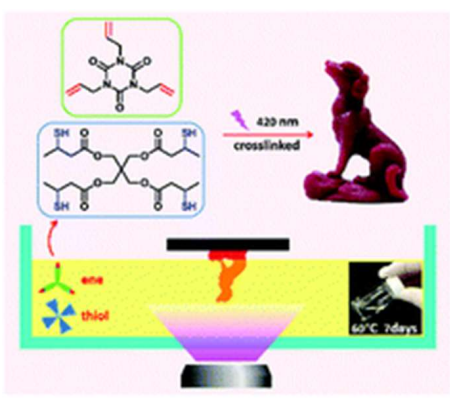

Figure 3.4 An example of thiol-ene photopolymer developed for DLP 3D printing. Reprinted with permission from[149]. Copyright (C) 2018 Royal Society of Chemistry. 


\section{Chapter 4 lonogels}

Electrolytes acting as ion transporting media are essential in biology and technology. In biological systems such as muscles and neurons, a subtle and complex ionic presence in the intracellular and extracellular environment is required for transferring cell signals and regulating cellular activities. In technological devices such as electrochemical cells, electrolytes acting as an ion reservoir and electronic insulator provide the required ionic pathways to complete electric circuits. As an alternative to liquid electrolytes, gel electrolyte has been widely used in numerous applications including supercapacitors, electrochemical sensors, organic transistors, electrochromic smart devices, dye-sensitized solar cells and electroactive polymer actuators. Ionogels, which confine ionic liquids within a three-dimensional solid-state matrix, are a new type of gel electrolytes. In this chapter, some basic information about ionogels is presented.

\section{1 lonic liquids}

In general, ionic liquids are described as molten organic salts with low melting points[150]. They consist entirely of ions so that the physicochemical property is significantly different from molecular liquids and can be easily modified by selecting a suitable pair of cation and anion amongst many possibilities. The most popular anions and cations used in ionic liquids are presented in Figure 4.1[151]. A set of extraordinary characteristics of ionic liquids include extremely low vapor pressure, good chemical and thermal stability, anti-flammability, high ionic conductivity and large electrochemical windows[150,152]. They can also be used as solvents for organic, polymeric and inorganic species for various synthesis, catalysis and separation processes[153, 154]. These exceptional properties are the reason for their growing use as alternative electrolyte in advanced electrochemical devices like fuels cells, organic transistors, batteries, supercapacitors and conducting polymer actuators[155-157]. 

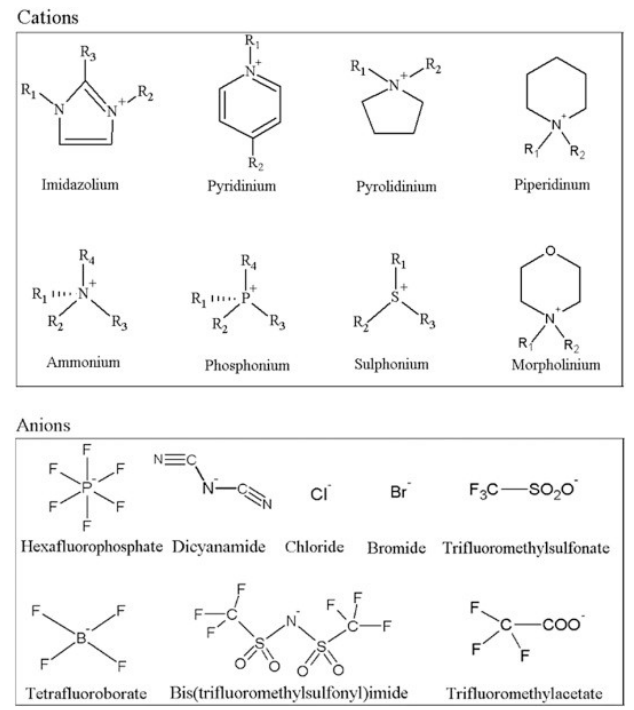

Figure 4.1 Most popular cations and anions of ionic liquids[151].

\section{2 lonogels}

To be applied in a solid-state device, there is a need to immobilize ionic liquids within a solid matrix as their liquid state can cause leakage issues and complicates fabrication process. To overcome the outflow problem, ionogels have been introduced. They are a group of new hybrid materials which confine ionic liquids within a three-dimensional organic, inorganic or composite solid network[158]. This confinement of ionic liquids allows the development of electrolyte materials that offer some exceptional properties including shape forming ability, mechanical flexibility and stretchability, optical transparency and excellent ionic conductivity by combining the properties of the solid matrix network and the ionic liquids. Thus, they have considerably expanded the application areas of ionic liquids and have been studied in both basic and applied materials science over the past decades.

\subsection{Properties of ionogels}

\subsubsection{Mechanical and physical properties}

The mechanical and physical properties of ionic liquids alone are greatly improved by the incorporation into a solid matrix, forming an ionogel. Generally, the solid fraction of ionogels in the case of silica matrix can be low (2-3\%) and of the order of $10 \%$ in the case of polymer matrices[159]. This low content of solid in ionogels not only changes the physical appearance 
of ionic liquid from fluid into gel-like, but also provides many other advantageous properties such as mechanical robustness, dimension stability, and improved thermal stability. Depending upon the nature of the solid matrix and its composition, the mechanical properties of ionogels vary from rigid solid to soft material. Highly flexible and stretchable ionogels can also be achieved even with a very low solid content[160]. This accelerates the development of durable and recoverable electrochemical devices that are able to endure repeated mechanical bending, folding or extension[161]. Flexible ionogels with low Young's modulus is especially beneficial to the performance of soft electrochemical actuators because actuators with soft ionic conducting layer generate a large bending motion. The solid-like nature of ionogels also easily allows various dimensions or shapes of ionogels to be fabricated down to the micro or nano scale. Other physical properties such as thermal stability is improved by addition of inorganic matrices with high thermal stability.

\subsubsection{Ionic conductivity}

The most important property of ionogels especially for their application in various electrochemical devices is the ionic conductivity. Ionogels with high ionic conductivity provide fast ion intercalation or deintercalation and thus allow rapid operation of the electrochemical devices like conducting polymer actuators. Ionic conductivity of ionic liquids depends on many parameters such as ion aggregation, viscosity, temperature, and water contents. Clusters or aggregates formed by ion species due to the ionic interactions in ionic liquid reduce its conductivity while dilution of ionic liquid with low-viscosity solvents increases its conductivity[162]. For ionogels, confined ionic liquids are predominantly responsible for ionic conductivity. The conductivity of ionogels shows a threshold behavior starting from insulating to ion conducting with increased the loading of ionic liquid, which reflects the phase changes from discontinuous microdroplets to a percolating state in the solid matrix[163]. Compared with pure ionic liquids, ionogels usually show a lower conductivity in most reported cases since lower concentration of the conducting medium is involved[162]. A liquid level conductivity can be obtained by reducing the solid matrix to the minimum. However, increasing the ionic liquid loading usually leads to a loss of mechanical integrity of ionogels. A higher conductivity is obtained in a ternary ionogel system, in which another low-viscosity solvent is added[164]. The ionic conductivity is also affected by the interaction between the solid matrix and free charge carriers in ionic liquid as some inorganic fillers or organic groups can enhance the dissociation of the ion pair. In addition, the chemistry used for the synthesis of ionogels influences the conductivity. For example, some sol-gel methods for ionogels preparation can release water, alcohol and other by-products that stay within the in-situ formed ionogels and affect the conductivity[165].

\subsubsection{Morphology}

For ionogels with an inorganic matrix, a two-phase structure, in which the solid inorganic matrix and ionic liquid phases percolate throughout each other, is usually formed[162]. 
However, the morphology of ionogels in the case of polymer matrices is more complicated as the compatibility of ionic liquid with the polymer matrix is a key factor for morphology. Ionogels synthesized by in-situ polymerization in ionic liquid or by solvent casting method can lead to phase separated materials with nano- to micro-sized ionic liquid domains if polymer matrices are not compatible with ionic liquid[159]. For miscible polymer matrix, the ionic liquid is held effectively inside the polymer matrix without phase separation. Such a morphological difference of ionic liquid inside the polymer materials can be reflected by their thermal properties. The ionogel with fully compatible components shows only one glass transition temperature ( $\mathrm{Tg}$ ) between that of neat ionic liquid and the pure polymer matrix. For phase separated ionogels, two Tg values derived from the polymer matrix and ionic liquid are observed[159]. Therefore, the compatibility between polymer matrix and ionic liquid creates a significant impact on the morphology and physical properties of the resulting ionogels. These effects can be used to create some novel materials with nanoscale structures by choosing an appropriate combination of ionic liquid and the polymer matrix. For example, block copolymers with incompatible polyethylene or polystyrene blocks and compatible polyethylene oxide blocks can form unique self-assembled structures in ionic liquids with special pathways to facilitate ion transportation[166,167]. Another example is the use of some tri-block copolymers with thermoresponsive blocks for smart ionogels that exhibit phase separations in ionic liquid upon temperature changes (Figure 4.2).

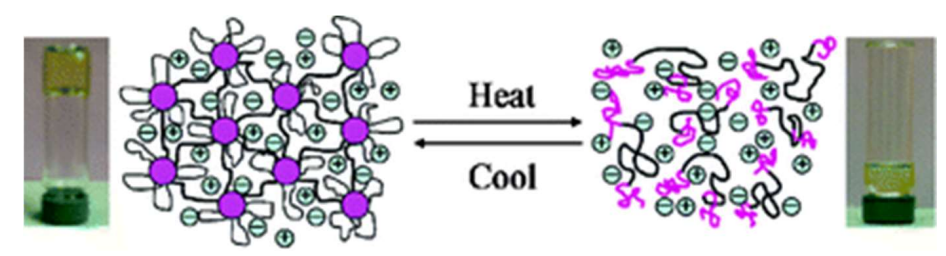

Figure 4.2 An ionogel self-assembled from triblock copolymer with proper end-blocks in ionic liquid showing thermoreversible gelation upon temperature changes. Reprinted from permission from[168]. Copyright (C) 2007 The Royal Society of Chemistry.

\subsection{Classification of ionogels}

\subsubsection{Organic, inorganic and composite ionogels}

Ionogels can be classified based on various criteria as schematically shown in Figure 4.3[159]. The most popular is the classification by the nature of solid network matrix, which can be classified as inorganic, organic, or organic-inorganic composite. The inorganic ionogels are prepared by sol-gel methods or impregnation of ionic liquids with oxide particles or carbon nanotubes. The most used synthetic method is the sol-gel process, which involves reactions like hydrolysis and condensation of inorganic oxide precursors. Depending on the reaction 
conditions and employed precursors, ionogels with different morphologies ranging from porous to dense bulk states are obtained[169]. Organic ionogels are prepared with low molecular weight organogelators or polymers. Gelation of ionic liquids with organogelators such as carbohydrates, amino acids or gluconic acid derivatives occurs due to various types of supramolecular bonding like $\pi-\pi$ interactions, hydrogen bonding, or electrostatic interactions. For polymer matrix, three possible ways to incorporate ionic liquids are polymerization of monomers in ionic liquid, solvent casting and physical doping of polymer materials with ionic liquids. Composite ionogels are typically based on polymer matrices reinforced with inorganic additives.

\subsubsection{Physical gels and chemical gels}

Another classification of ionogel is determined by how the solid matrix is formed. In physical gels, the formation of the three-dimensional solid network occurs due to weak and reversible physical interactions like hydrogen bonds, crystallite junctions and hydrophobic effects. They can be obtained by either using an organic gelator or inorganic additives which coagulate the ionic liquid. Physical gels are generally presented in the form of jelly, paste or slurry, without a strong mechanical strength and dimensional stability[150]. Chemical gels are created by incorporating the ionic liquid in a covalently formed host matrix. Chemical gelation is superior to physical gelation in terms of stable integration and mechanical resistance because of irreversible and covalent chemical bonds within the network.

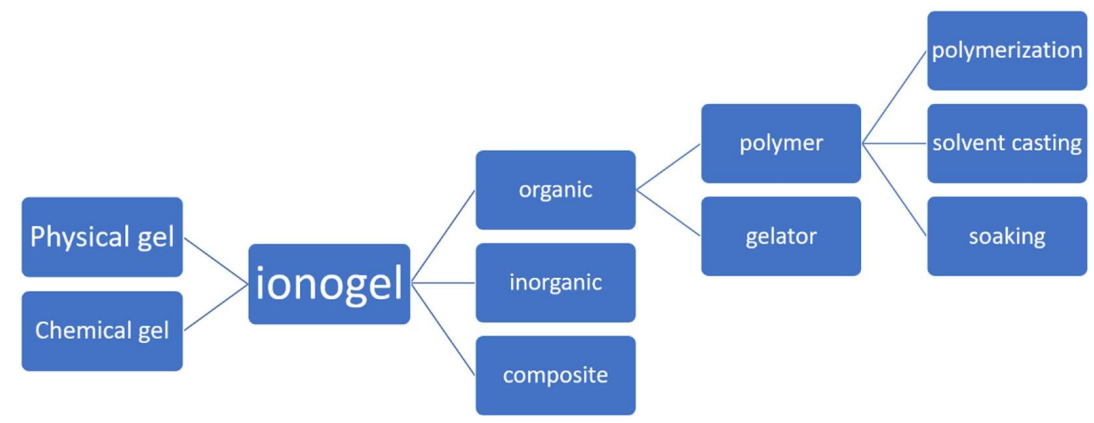

Figure 4.3 Classification of ionogels.

\subsection{Polymer based ionogels}

Ionogels that use polymer matrices to immobilize ionic liquids have a combination of the mechanical properties of a polymer and the characteristic properties of ionic liquids. A good 
polymer matrix for ionogels should meet several criteria: (1) good solubility and compatibility with the ionic liquid; (2) chemical groups facilitating the separation of ion pairs; (3) low glass transition temperature (Tg); (4) fast segmental dynamics of polymer chain; (5) high molecular weight; (6) high electrochemical stability; and (7) high degradation temperature. Many polymer-based ionogels are obtained simply by dissolving the polymer matrix in the ionic liquid together with a volatile organic solvent to prepare a homogeneous solution, which is subsequently cast and dried to evaporate the added solvent. Polymer materials used in the solution casting method include homopolymers, block copolymers and fluoropolymers like poly(vinylidene fluoride) (PVDF) and poly(vinylidenefluoride-co-hexafluoropropylene) (PVDF-HFP)[170, 171]. Natural polymers are also increasingly used for preparation of ionogels, like chitin, cellulose, gelatin, or xanthan gum[172, 173]. The casting method allows ionic liquid to be mixed in polymers in various proportions. However, the mechanical properties of the obtained ionogels is often limited and further improvement by crosslinking is needed. Another possibility of preparing ionogels is the simple physical soaking process in which porous polymer matrices such as interpenetrated polymer networks (IPN) are prefabricated and then the matrices are soaked with ionic liquids[75]. This simple impregnation method enables the use of crosslinked polymer matrices, which have a better mechanical stability. However, it does not allow for the exact control of the absorbed amount of ionic liquid because the maximum ionic liquid composition is limited by the swelling capacity of the polymer matrices.

Another method to prepare polymer ionogel is based on in-situ polymerization of monomers in ionic liquid or crosslinking of dissolved linear polymers. Ionogels are obtained in one single step after the completion of polymerization. Different types of polymer synthesis techniques such as traditional free radical polymerization, ionic polymerization, living free radical polymerizations, as well as coordination polymerizations have been used for preparing ionogels $[174,175]$. The polymerization method allows a full control of the ionogel composition and the use of a crosslinked polymer network. At the same time, the use of volatile solvents is avoided. Cross-linking network formed during polymerization improves the mechanical properties and dimension stability without losing significant conductivity. In addition, polymerization in ionic liquids enables to prepare ionogels with higher molecular weight polymers and in some cases a notable acceleration of the polymerization kinetics in ionic liquid is observed[174].

\subsection{Photopatternable ionogels}

Polymerization in ionic liquid can be initiated with the use of thermal initiators or photoinitiators. Thermal initiation is widely used but it requires relatively high temperatures and long reaction time. It is preferable for preparation of thick ionogels as thermal energy is easily transferred into the inside of thick materials. Photoinduced polymerization presents several advantages over thermal initiation such as rapid polymerization kinetics from seconds to minutes, low reaction temperature (often at room temperature), low energy required, being transferable to industrial scale, and spatial resolution temporal and spatial control. The capability to control polymerization temporally and spatially for ionogel preparation leads to the development of micropatternable ionogels via photolithographic techniques and the formation of possible complex geometric microstructures[176]. The advantages of 
photopatternable ionogels and their photolithographic patterning processes are that traditional photolithography is a rapid and precise process for high-definition patterns and becomes a more general and accessible technique, which is traditionally used in silicon-based microfabrication processes. Photopatterning allows to create high definition ion conducting micropatterns in a rapid and batch production manner compared to other micropatterning such as laser ablation or microcontact printing. Meanwhile, micropatterns and microstructures of polymer gel electrolytes are needed to fabricate flexible microelectrochemical devices on a large scale. Photopatternability of an ionogel can also simplify the fabrication process because it can be used as a negative photoresist to pattern subsequent layers[177]. One example of photopatternable ionogel systems reported in the literature is prepared from a complex ABAtriblock copolymer ion gel as high-capacitance gate materials in an array of thin film organic transistors (TFTs)[178]. A synthesized triblock copolymer with photosensitive groups in the end blocks is used as the ionogel matrix, which is crosslinkable by UV irradiation (Figure 4.4).

Besides the micropatternability, it is essential that photopatternable ionogels should combine a high ionic conductivity with good mechanical properties for use in flexible electrochemical devices. Ionogels with reactive surfaces are also extremely useful for improving the adhesion between the different layers in most electrochemical devices, which usually have a common multi-layered structure such as conducting polymer actuators. In addition, ionogels with tunable mechanical properties are needed to meet the exact mechanical requirements in the fabrication of various flexible and stretchable microdevices. There is a need existing for photopatternable ionogel materials whose mechanical properties as well as the surface properties are tailorable. To meet those demands, novel routes of polymer network formation through which such ionogels can be prepared, is explored in this thesis.

(a)

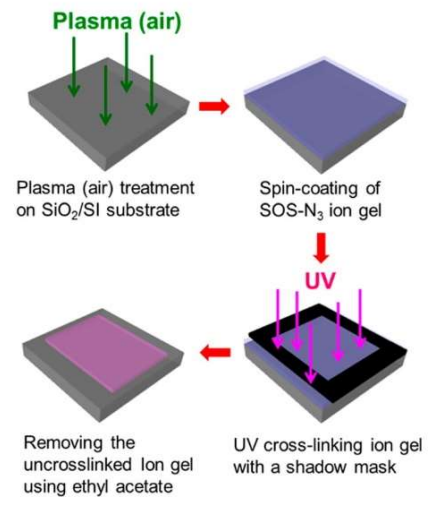

(b)

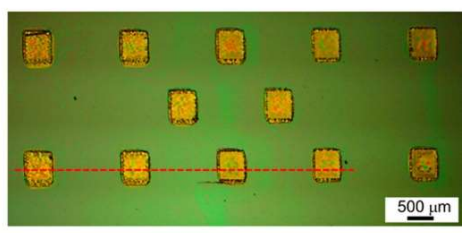

(c)

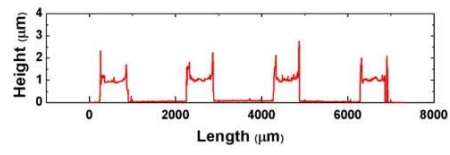

Figure 4.4 (a) Photolithographic procedures of patternable ionogels from photoinitiated crosslinking of triblock copolymer, (b) photograph of ionogel micropatterns and (c) thickness profile of ionogel micropatterns. Reprinted with permission from[178]. Copyright (C) 2014 American Chemical Society. 


\section{7 lonogels with 3D microstructures}

Besides the planar micropatterns, complex 3D patterns and structures with submicron or nanoscale resolution can be prepared from photocurable ionogels using multiphoton polymerization (MPP) lithography techniques, which is a high-definition direct laser writing method with resolution beyond the diffraction limit of light[179]. Ionogels with threedimensional woodpile microstructures are produced from phosphonium and imidazolium based photopatternable composite ionogels as shown in Figure 4.5[180]. The hybrid material contains both $\mathrm{Si}$ and zirconate $\mathrm{Zr}$ ) acrylate modified alkoxides, which can be polymerized via UV light illumination. These inorganic and organic components form the basis of composite ionogels, which demonstrate a sub-micron biphasic morphology. The results show that the inorganic zirconate network is important to maintain the mechanical stability of the $3 \mathrm{D}$ microstructures created by two-photon polymerization (2PP). However, novel photopatternable ionogel systems are needed for further development to prevent ionic liquid leaching from the gel matrix and to create more advanced microstructures. The amenability of photocurable ionogels to 3D microstructures suggests its tremendous potential for use in sophisticated 3D microsystems with high precision[181].
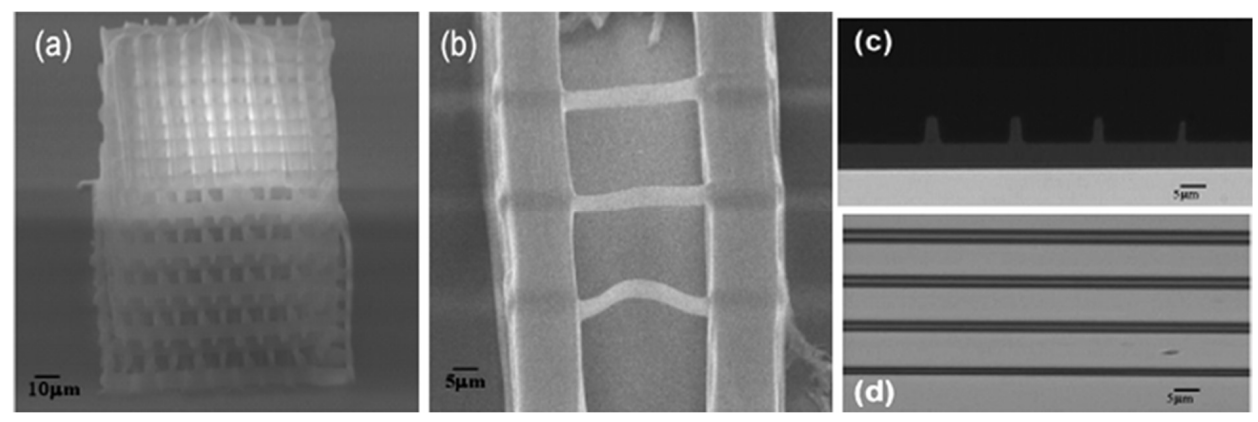

Figure 4.5 Three-dimensional woodpile microstructures ( $a$ and b) by two photons polymerization and two dimensional micropatterns (c and d) from hybrid ionogels. Reprinted from permission from[180]. Copyright (C) 2011 Royal Society of Chemistry.

\subsection{Functional ionogels}

Besides the traditional ionic conductivity of ionogels, different kinds of functional ionogels with new functionalities have also been developed as a more advanced form of ionogels in recent years. Functionalization of ionogels is prepared by incorporating functional molecules, sensing molecules, metal-chelating ligands, metal complexes, catalysts, fluorescent metal complexes and nanoparticles either in the ionic liquid phase or in the immobilized solid matrix[165]. The encapsulation of designed molecules creates infinite possibilities of functionalities and establishes new ways to design functional materials especially in the 
application areas of sensors, electrochemical display, catalysts and energy conversion devices. For example, thermotolerant ionogels can allow a battery able to operate at harsh conditions, preventing failure or explosion[182]. Ionogels with incorporated color-changing abilities can extend the application of ionogels in smart windows and beyond[180]. Self-healing ionogels, which can easily repair their incidental damages, are also receiving great attention as they have great potential in advanced energy storage devices, artificial electronic skin and soft actuators[183, 184]. Functional ionogels with versatile and practical applicability could be one emerging and promising direction in the future.

\subsection{Polymerized ionic liquids}

Conventional ionogels are generally formed by confining ionic liquid in a solid matrix where there is no covalent chemical bonding between these two components. These ionogels suffer from leaching problem after a certain period of service time as the ionic liquid are just physically trapped inside the solid matrix. Another limitation of ionogels is that the transference number of a specific ion of interest is difficult to control because both ions (anions and cations) are mobile in ionic liquids[185]. Unlike ionogels, polymerized ionic liquids have attracted significant interest because they are usually single-ion conductors and combine the superiorities of ionic liquid but with a macromolecular architecture. Polymerizable ionic liquids possess advantages as polymer materials concerning their facile processability, mechanical properties, and chemical stability. There are two main strategies for covalently immobilizing ionic species in the polymeric chain either as a side pendant group or as segment of the main backbone chain[186]. For example, polymerized ionic liquids have been synthesized from polymerizable ionic monomers using free radical polymerization techniques. The limitation of polymerized ionic liquids in the practical application is their poor ionic conductivity at ambient temperature due to strong ionic interactions. To achieve a highly effective single-ion conductor, a high degree of free charge carriers is required. Introducing strong electron-withdrawing chemical groups near the free charge carriers in the polymeric chains can weaken the electrostatic interaction and is beneficial to enhance ion mobility and conductivity[187]. Other possible strategies are exploited by designing polymeric backbones with low $\mathrm{Tg}$, addition of functional fillers, copolymerizing with other monomers such as styrene and acrylonitrile, and blending with other polymer matrices such as PEO, PVDF, PVDF-HFP to enhance the ionic conductivity as well as the mechanical properties[188]. Covalent network by crosslinking polymerized ionic liquids also improves the mechanical properties and resistance to dissolution[189].

\subsection{Application of ionogels in soft EAP actuators}

Because ionogels present a diversity of excellent physical, conductive and electrochemical properties, they have been applied in various electrochemical devices such as organic transistors, flexible batteries, supercapacitors, dye-sensitized solar cells, and pressure sensors[190, 191]. Ionogels are also currently investigated for their use in soft EAP actuators like dielectric elastomer actuators, conducting polymer actuators and bulky gel actuators[184]. 
Their application in dielectric elastomer actuators is proved by a highly stretchable, transparent, and nonvolatile ionogel as the compliant ionic electrodes (Figure 4.6). The nonvolatility and stretchability of the ionogel enable large deformations in open air. The optical transparency of the ionogel allows novel applications in the areas of focus-tunable lenses, transparent wearable loudspeakers, and active-noise-cancelling devices. Ionogels also receive significant attention in conducting polymer based electrochemical actuators[192]. They generally have a typical layered structure consisting of an ion conducting layer sandwiched between two conducting polymer electrodes, which generates a bending motion due to the differential volume changes of the conducting polymer electrodes by ions insertion/expulsion under the applied voltage. Conventionally, aqueous or organic volatile electrolytes are used as ion conducting materials in conducting polymer electrochemical actuators. However, the solvent evaporation in the electrolyte materials reduces the ionic conductivity and limits the lifetime and performance of the actuators. Improved lifetime and stability of conducting polymer actuators in open air using ionogels as a non-volatile electrolyte is demonstrated without the evaporation issues. In addition, ionogels not only act as electrolyte materials but also as electrode materials in carbon materialsbased electrochemical actuators[193]. These actuators are prepared by sandwiching fluorinated copolymer based ionogels with two carbon nanotube bucky gel electrodes using a layer-bylayer casting method. Those polymer-free carbon nanotube electrodes are obtained using well dispersed super-growth single walled nanotubes in ionic liquid[194]. Carbon nanotube fillers in the bucky gel endow them with excellent electronic conductivity and enhanced mechanical properties. Actuation performance with a large displacement up to $5 \mathrm{~cm}$ is achieved at a frequency of $1 \mathrm{~Hz}$ for these actuators fully based on ionogels, which can be applied for instance in intelligent soft robots, electrochemical mechanical sensors.

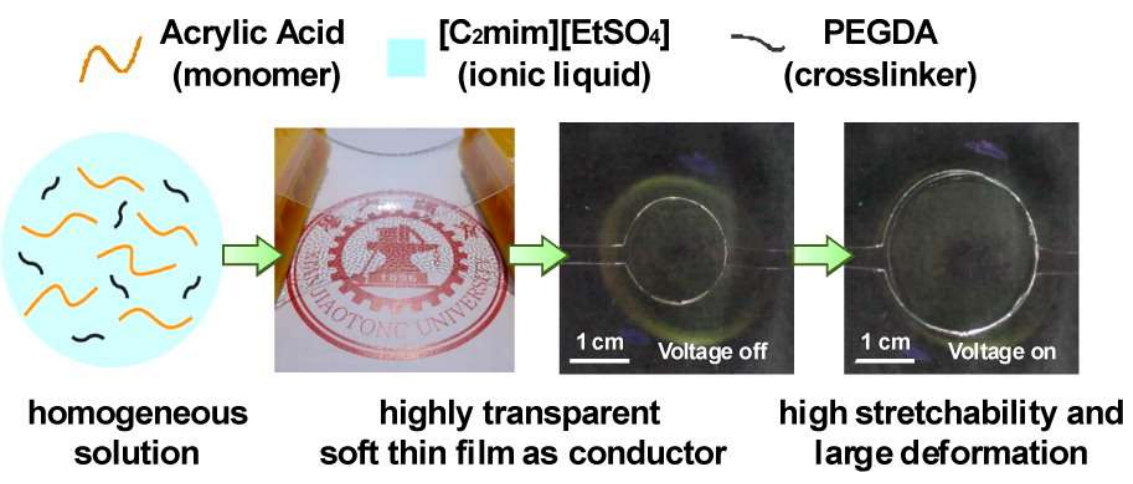

Figure 4.6 Dielectric elastomer actuators with transparent and stretchable electrodes made from ionogel. Reprinted with permission from[195]. Copyright (C) 2014 American Chemical Society. 


\section{Chapter 5 Summary of the papers included}

\section{Paper I}

Title: Development of polypyrrole based solid-state on-chip microactuators using photolithography

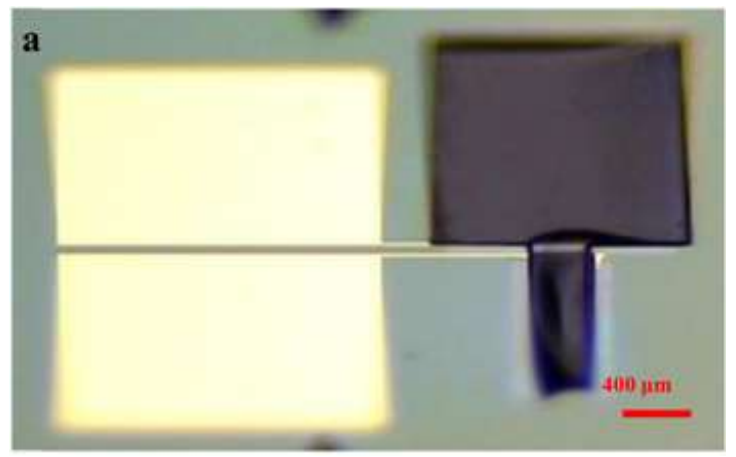

Figure 5.1 A photograph of conducting polymer based solid state microactuators prepared from photolithography.

In Paper I, a new microfabrication process has been developed to fabricate conducting polymer microactuators that can work outside of a liquid electrolyte. These solid state microactuators in the range of 100-1000 $\mu \mathrm{m}$ were created by combining standard photolithographic techniques, wet etching, with micropatterning of the conducting polymer polypyrrole by electropolymerization. A lateral design of electrode configuration was chosen instead of a typical sandwiched structure. Photopatternable BEMA gels containing an organic electrolyte were prepared with traditional free radical polymerization and were immobilized on two polypyrrole electrodes. The fabricated microactuators were electrochemically active since electrochromism and some small movement were observed. However, the observed performance of the solid-state microactuators was worse than that of the microactuators operating in the liquid electrolyte. The low ionic conductivity of the BEMA gel micropatterns in comparison with that of the liquid electrolytes is the most probable reason. Nevertheless, a scalable and reliable microfabrication method is demonstrated for fabrication of individually controllable solid-state microactuators which are essential for complex microsystems fabrication. It also shows the need to develop enhanced gel electrolyte micropatterns combining high ionic conductivity and enhanced mechanical properties with advanced polymerization techniques as presented in Papers II and IV. 


\section{Paper II}

Title: Highly conductive, photolithographically patternable ionogels for flexible and stretchable electrochemical devices
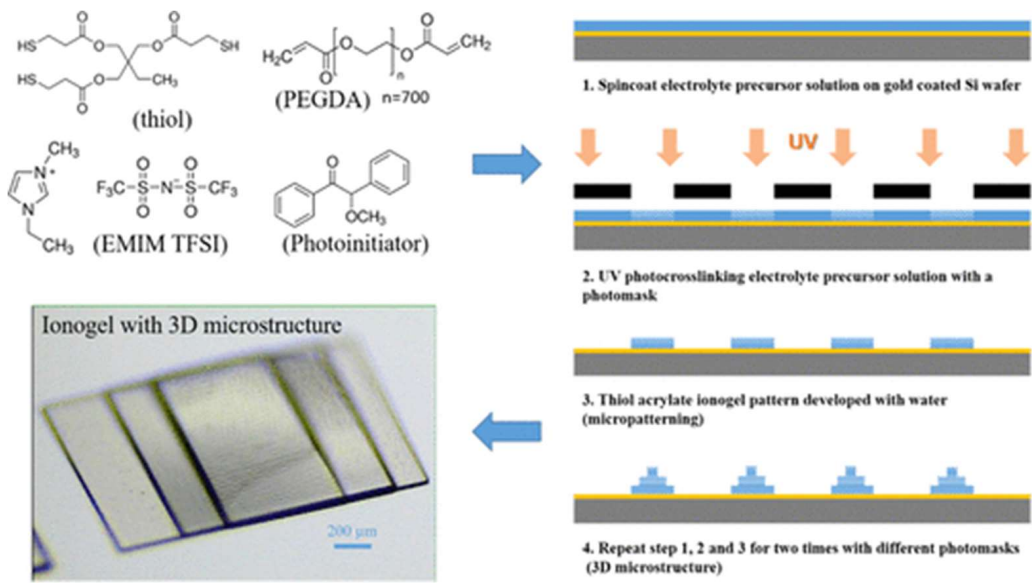

Figure 5.2 3D microstructures of thiol acrylate based ionogels fabricated from photolithographic process.

To improve the micropatterns of solid polymer electrolytes in Paper I, a new family of photopatternable solid polymer electrolyte combining a soft mechanical property and a high ionic conductivity was developed. The solid polymer electrolyte, which can also be called an ionogel, was synthesized by in situ mixed mode photopolymerization of thiol acrylate monomers in the EMIM TFSI ionic liquid. The photopatternability of these thiol acrylate photopolymers was demonstrated for its use as an ion conducting photoresist in conventional photolithography and in a soft lithography process to obtain micropatterned surface on the ionogel film. The measured ionic conductivity for the casted bulk films is $2.4 \times 10^{-3} \mathrm{~S} / \mathrm{cm}$ and the conductivity for the photolithographically patterned films is $4.7 \times 10^{-5} \mathrm{~S} / \mathrm{cm}$ after the development process with water as the developer. Advanced 3D microstructures of ionogels were fabricated from photolithographic process by exploiting the reactive surface and the photopatternability. Electrochromic micropatterns and soft twisting conducting polymer actuators were prepared to show their application in flexible electrochemical devices. 


\section{Paper III}

Title: Fully disposable active microfluidics enabled by a versatile polymer actuator system for pumps, valves and injectors
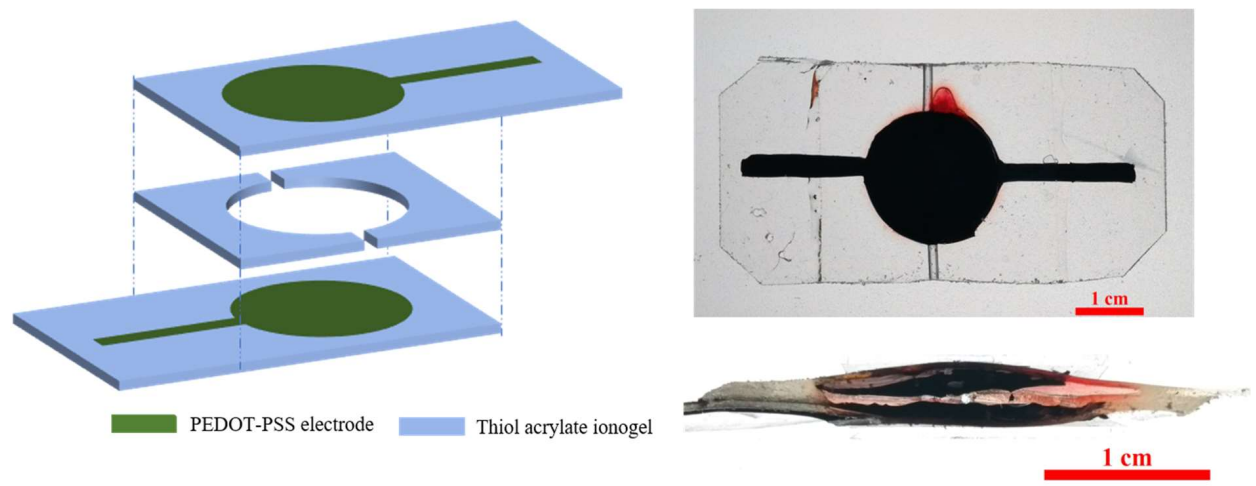

Figure 5.3 Illustration and photographs of all-polymer actuator systems for active microfluidic components.

To further expand the application of the thiol acrylate ionogels as developed in Paper II, a novel type of diaphragm actuator system, called Double Diaphragm Active Polymer Actuator (DDAPA), has been developed as a single modular block that can be repurposed to diverse active microfluidic components. The commercially available conducting polymer PEDOT:PSS was used as the actuating material and thiol acrylate based ionogels were used as polymer gel electrolyte and base material in the trilayer diaphragm actuator. The ionogel precursor solution was also utilized as an adhesive to bond two diaphragm actuators and structural layer together to form the DDAPA. The versatility of such bonding methods was also demonstrated by constructing complex devices with multiple diaphragm actuators. The bonded DDAPA showed good adhesion and no leakage. Flow rate measurements show the capability of the DDAPA to inject, regulate flow, and unidirectionally pump fluids up to $112 \mu \mathrm{L} / \mathrm{min}$ when coupled with a $3 \mathrm{D}$ printed unibody check-valve. This result demonstrates that a low-cost conducting polymerbased diaphragm is an attractive actuation choice of active control for fully disposable autonomous microfluidics. 


\section{Paper IV}

Title: Tailorable, 3D structured and micro-patternable ionogels for flexible and stretchable electrochemical devices<smiles>CCC(COC(=O)CCS)(COC(=O)CCS)C(=O)O</smiles><smiles>CCN(CC)CC</smiles>

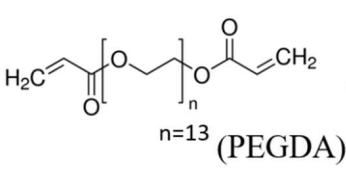<smiles></smiles><smiles>O=S(=O)(OS(=O)(=O)C(F)(F)F)[Mg][Mg]</smiles>

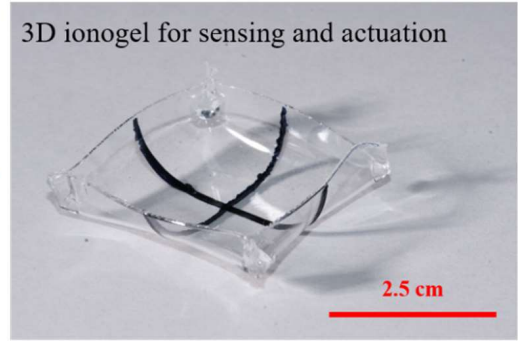

Figure 5.4 3D ionogel for sensing and actuation prepared from thiol acrylate Michael addition.

To obtain even better mechanical and tunable surface properties and eliminate the oxygen inhibition issue completely, a novel platform to prepare next generation ionogels is established with thiol acrylate Michael addition chemistry. The ionogels were synthesized by mixing trithiol crosslinker, poly(ethylene glycol) diacrylate and ionic liquids (EMIM TFSI) with the catalytic amount of triethylamine (TEA). Polymerization kinetics was investigated with FTIR techniques, and the results showed that the ionic liquid is also a co-catalyst accelerating thiol acrylate Michael addition reaction. A high conversion of functional groups and rapid reaction kinetics were achieved in diluted reaction, which is in sharp contrast to a slow TEA catalyzed bulk reaction. Three different approaches, off-stoichiometry, methacrylate addition, and dithiol addition, were used to prepare ionogels with active surface and enhanced mechanical properties. Flexible and stretchable ionogel films with Young's modulus varying from $0.3 \mathrm{MPa}$ to $2.1 \mathrm{MPa}$ and the strain up to $155 \%$ were achieved. Their compatibility with both photolithography and soft imprinting lithography were also investigated. Off-stoichiometric formulations results in an ionogel with well-controlled unreacted chemical groups on the surface. To show the potential of the reactive surfaces on ionogel, two electrochemical devices, a tube actuator and a boxshaped taxel, were easily created. These results illustrate that these photopatternable and tailorable ionogels from thiol acrylate Michael addition can be used as soft actuators, flexible haptic arrays, and steerable catheters in in a wide range of future electrochemical applications. 


\section{Chapter 6 Outlook}

Photopatternable gel electrolytes based on various polymer network chemistries are synthesized and extensively characterized. In addition, their applications as electrolyte patterns in the microfabrication of actuators and electrochromic patterns are demonstrated. The use of such micropatternable polymer electrolytes in the standard photolithography process could be easily adapted and extended to fabricate other electrochemical microdevices like microsupercapacitors or microbatteries.

The versatile thiol acrylate chemistry allows us to obtain photopatternable ionogel micropatterns and microstructures using standard photolithographic techniques in an easier way compared with conventional free radical polymerization. However, these electrolyte micropatterns are still limited by some issues. The physically trapped ionic liquids can leach out from the polymer gel matrix over long time and the development step in the photolithographic process will remove some of the incorporated ionic liquids even using ionic liquid-immiscible solvent as the developer. These limitations create some opportunities for further improvement of photopatternable polymer electrolytes. In contrast to these ionogels, polymerizable ionic liquids feature a chemically bonded ionic conducting species in the polymeric chain[196]. It combines the exceptional characteristics of ionic liquids with the properties of macromolecular structures and provides unusual functions and characteristics such as tunable ionic conductivity, improved chemical and electrochemical stability and thermodynamic stability[197]. Future research should focus on the development of photopatternable polymer electrolyte with a polymerizable ionic liquid architecture based on versatile thiol acrylate Michael chemistry.

The excess functional groups especially thiol groups resulting from thiol acrylate mixed mode photopolymerization or off-stochiometric thiol acrylate Michael reaction are exploited in the direct bonding process to construct various types of conducting polymer-based actuators with novel applications, as demonstrated in this thesis by DDAPA actuators for active microfluidic devices (Paper 3) and tube actuator (Paper 4). However, only the functional groups on the surface are used in these cases and further exploitation could be done. As noted in the chapter 3 , thiol groups can react with various substrates in a click chemistry which allows chemists to create, functionalize or modify a wide variety of molecules. Novel materials with exceptional physical, chemical and mechanical characteristics can be designed for a specific application. This shows further potential in the development of thiol acrylate based ionogels by covalent incorporation of functional molecules, metal-chelating ligands, catalysts, sensing molecules, fluorescent molecules or nanoparticles into the polymer network by various thiol-based click chemistry, which could establish new routes to design advanced functional materials for applications in the areas of sensors, display devices, electrochemical energy materials or catalysis. For example, the incorporation of an electrochromic dye via thiol chemistry into ionogels will lead to the development of a patternable electrochromic display for smart windows and beyond. For practical applicability and functional versatility, functional ionogels could be one emerging and promising direction in the future development.

Besides the standard photolithographic microfabrication method, tremendous potential lies in additive manufacturing techniques such as single-photon or two-photon microstereolithography for their ability to form arbitrary 3D micro and nano structures with high-resolution from 
photopolymerizable materials[198, 199]. This fabrication method may allow us to develop sophisticated 3D polymer electrolyte patterns and structures with submicron or nanoscale resolution from photoinduced thiol acrylate-based polymer electrolytes and thus suggest its huge potential for use in electrochemical microdevice fabrication. For example, it may allow the development of advanced 3D electroactive polymer micro- and nanoactuators if possible photopatternable electrode and electrolyte materials are available. The establishment of new fabrication methods for microactuators using such 3D microfabrication techniques will certainly expand the application areas of soft electrochemical microactuators in future integrated microsystems.

Besides the novel applications demonstrated in this thesis, the developed ionogels are currently exploited as a stretchable electrolyte in fiber and fabric based conducting polymer actuators that can operate in open air. Transforming ubiquitous fiber and fabric into soft wearable actuation materials is advantageous because they can be rationally integrated in different designs and upscaled in an efficient production manner using traditional textile processing techniques including weaving and knitting[200]. These wearable actuators are an exciting soft actuation technology with many possibilities for applications such as exoskeleton-like soft robotic suits. Such soft robotic devices with the wearable actuators would bridge the gap between soft robots with humans in their daily life especially for the aging population, which is a current worldwide issue for human society. 


\section{References}

1. Bloom, D.E., D. Canning, and A. Lubet, Global population aging: Facts, challenges, solutions \& perspectives. Daedalus, 2015. 144(2): p. 80-92.

2. Yoshino, N., C.J. Kim, and P. Sirivunnabood, Aging Population and its Impacts on Fiscal Sustainability. 2019.

3. Wehner, M., et al., An integrated design and fabrication strategy for entirely soft, autonomous robots. Nature, 2016. 536(7617): p. 451.

4. Rus, D. and M.T. Tolley, Design, fabrication and control of soft robots. Nature, 2015. 521(7553): p. 467.

5. Medina - Sánchez, M., et al., Swimming microrobots: Soft, reconfigurable, and smart. Advanced Functional Materials, 2018. 28(25): p. 1707228.

6. Electroactive Polymers as Artificial Muscles: Capabilities, Potentials and Challenges, in Robotics 2000. p. 188-196.

7. Bar-Cohen, Y. and Q. Zhang, Electroactive polymer actuators and sensors. MRS bulletin, 2008. 33(3): p. 173-181.

8. Ning, C., et al., Electroactive polymers for tissue regeneration: Developments and perspectives. Progress in Polymer Science, 2018. 81: p. 144-162.

9. Bar-Cohen, Y., Electroactive polymers as artificial muscles: A review. Journal of Spacecraft and Rockets, 2002. 39(6): p. 822-827.

10. Trivedi, D., et al., Soft robotics: Biological inspiration, state of the art, and future research. Applied bionics and biomechanics, 2008. 5(3): p. 99-117.

11. Carpi, F., et al., Electroactive polymer actuators as artificial muscles: are they ready for bioinspired applications? Bioinspiration \& biomimetics, 2011. 6(4): p. 045006.

12. Smela, E., Conjugated Polymer Actuators for Biomedical Applications. Advanced Materials, 2003. 15(6): p. 481-494.

13. Maziz, A., et al., Demonstrating $\mathrm{kHz}$ Frequency Actuation for Conducting Polymer Microactuators. Advanced Functional Materials, 2014. 24(30): p. 4851-4859.

14. Gaihre, B., et al., Effect of electrolyte storage layer on performance of PPy-PVDF-PPy microactuators. Sensors and Actuators B: Chemical, 2011. 155(2): p. 810-816.

15. Jager, E.W., E. Smela, and O. Inganäs, Microfabricating conjugated polymer actuators. Science, 2000. 290(5496): p. 1540-1545.

16. Wax, S.G. and R.R. Sands, Electroactive polymer actuators and devices. 1999 Symposium on Smart Structures and Materials. Vol. 3669. 1999: SPIE.

17. Romasanta, L.J., M.A. Lopez-Manchado, and R. Verdejo, Increasing the performance of dielectric elastomer actuators: A review from the materials perspective. Progress in Polymer Science, 2015. 51: p. 188-211.

18. O'Halloran, A., F. O'Malley, and P. McHugh, A review on dielectric elastomer actuators, technology, applications, and challenges. Journal of Applied Physics, 2008. 104(7): p. 071101.

19. Carpi, F., S. Bauer, and D. De Rossi, Stretching dielectric elastomer performance. Science, 2010. 330(6012): p. 1759-1761.

20. Jaiswal, M. and R. Menon, Polymer electronic materials: a review of charge transport. Polymer international, 2006. 55(12): p. 1371-1384.

21. Schwartz, B.J., Conjugated Polymers as Molecular Materials: How Chain Conformation and Film Morphology Influence Energy Transfer and Interchain Interactions. Annual Review of Physical Chemistry, 2003. 54(1): p. 141-172.

22. Ahonen, H.J., J. Lukkari, and J. Kankare, $n$-and p-doped poly (3, 4-ethylenedioxythiophene): two electronically conducting states of the polymer. Macromolecules, 2000. 33(18): p. 6787-6793.

23. Mastragostino, M., C. Arbizzani, and F. Soavi, Conducting polymers as electrode materials in supercapacitors. Solid state ionics, 2002. 148(3-4): p. 493-498. 
24. Smela, E., Microfabrication of PPy microactuators and other conjugated polymer devices. Journal of Micromechanics and Microengineering, 1999. 9(1): p. 1-18.

25. Kaur, G., et al., Electrically conductive polymers and composites for biomedical applications. RSC Advances, 2015. 5(47): p. 37553-37567.

26. Madden, J.D., P.G. Madden, and I.W. Hunter, Polypyrrole actuators: modeling and performance. SPIE's 8th Annual International Symposium on Smart Structures and Materials. Vol. 4329. 2001: SPIE.

27. Kim, J., et al., A Comparative Study of Conductive Polypyrrole and Polyaniline Coatings on Electro-Active Papers. Polymer Journal, 2006. 38(7): p. 659-668.

28. Zainudeen, U.L., M.A. Careem, and S. Skaarup, PEDOT and PPy conducting polymer bilayer and trilayer actuators. Sensors and Actuators B: Chemical, 2008. 134(2): p. 467-470.

29. Sadki, S., et al., The mechanisms of pyrrole electropolymerization. Chemical Society Reviews, 2000. 29(5): p. 283-293.

30. Heinze, J., Electrochemistry of conducting polymers. Synthetic Metals, 1991. 43(1): p. 28052823.

31. Gao, F., et al., Bioinspired Design of Strong, Tough, and Highly Conductive Polyol-Polypyrrole Composites for Flexible Electronics. ACS Applied Materials \& Interfaces, 2017. 9(7): p. 56925698.

32. Paradee, N. and A. Sirivat, Synthesis of poly (3, 4 - ethylenedioxythiophene) nanoparticles via chemical oxidation polymerization. Polymer International, 2014. 63(1): p. 106-113.

33. Winther-Jensen, B., et al., Vapor Phase Polymerization of Pyrrole and Thiophene Using Iron(III) Sulfonates as Oxidizing Agents. Macromolecules, 2004. 37(16): p. 5930-5935.

34. Stanke, D., M.L. Hallensleben, and L. Toppare, Oxidative polymerization of pyrrole with iron chloride in nitromethane. Synthetic Metals, 1995. 72(2): p. 159-165.

35. Li, Y., R. Tanigawa, and H. Okuzaki, Soft and flexible PEDOT/PSS films for applications to soft actuators. Smart Materials and Structures, 2014. 23(7): p. 074010.

36. Zhang, J., et al., Fast and scalable wet-spinning of highly conductive PEDOT:PSS fibers enables versatile applications. Journal of Materials Chemistry A, 2019. 7(11): p. 6401-6410.

37. Yao, B., et al., Ultrahigh-Conductivity Polymer Hydrogels with Arbitrary Structures. Advanced Materials, 2017. 29(28): p. 1700974.

38. Brooke, R., et al., Inkjet printing and vapor phase polymerization: patterned conductive PEDOT for electronic applications. Journal of Materials Chemistry C, 2013. 1(20): p. 3353-3358.

39. Winther-Jensen, B. and K. West, Vapor-Phase Polymerization of 3,4-Ethylenedioxythiophene: A Route to Highly Conducting Polymer Surface Layers. Macromolecules, 2004. 37(12): p. 45384543.

40. Wax, S.G. and R.R. Sands. Electroactive polymer actuators and devices. in Smart Structures and Materials 1999: Electroactive Polymer Actuators and Devices. 1999. International Society for Optics and Photonics.

41. Spinks, G.M., et al., Conjugated polymer actuators: fundamentals. Biomedical Applications of Electroactive Polymer Actuators, 2009. 195: p. 227.

42. $\mathrm{Wu}, \mathrm{Y}$., et al., Soft mechanical sensors through reverse actuation in polypyrrole. Advanced functional materials, 2007. 17(16): p. 3216-3222.

43. Tabard-Cossa, V., et al., Redox-induced surface stress of polypyrrole-based actuators. The Journal of Physical Chemistry B, 2005. 109(37): p. 17531-17537.

44. Yan, B., Y. Wu, and L. Guo, Recent Advances on Polypyrrole Electroactuators. Polymers, 2017. 9(9): p. 446.

45. Jager, E.W.H., E. Smela, and O. Inganäs, Microfabricating Conjugated Polymer Actuators. Science, 2000. 290(5496): p. 1540-1545.

46. Hara, S., et al., Free-standing gel-like polypyrrole actuators doped with bis (perfluoroalkylsulfonyl) imide exhibiting extremely large strain. Smart Materials and Structures, 2005. 14(6): p. 1501. 
47. Torop, J., A. Aabloo, and E.W. Jager, Novel actuators based on polypyrrole/carbide-derived carbon hybrid materials. Carbon, 2014. 80: p. 387-395.

48. Le, T.-H., Y. Kim, and H. Yoon, Electrical and Electrochemical Properties of Conducting Polymers. Polymers, 2017. 9(4): p. 150.

49. Temmer, R., et al., In search of better electroactive polymer actuator materials: PPy versus PEDOT versus PEDOT-PPy composites. Smart Materials and Structures, 2013. 22(10): p. 104006.

50. Bay, L., et al., Mechanism of Actuation in Conducting Polymers: Osmotic Expansion. The Journal of Physical Chemistry B, 2001. 105(36): p. 8492-8497.

51. Jafeen, M.J.M., M.A. Careem, and S. Skaarup, Speed and strain of polypyrrole actuators: dependence on cation hydration number. Ionics, 2010. 16(1): p. 1-6.

52. Melling, D., J.G. Martinez, and E.W.H. Jager, Conjugated Polymer Actuators and Devices: Progress and Opportunities. Advanced Materials, 2019. 31(22): p. 1808210.

53. Ding, J., et al., Use of ionic liquids as electrolytes in electromechanical actuator systems based on inherently conducting polymers. Chemistry of materials, 2003. 15(12): p. 2392-2398.

54. Madden, J.D., et al., Fast contracting polypyrrole actuators. Synthetic Metals, 2000. 113(1-2): p. 185-192.

55. Bay, L., et al., A Conducting Polymer Artificial Muscle with $12 \%$ Linear Strain. Advanced Materials, 2003. 15(4): p. 310-313.

56. Takashima, W., et al., Patternable bi-ionic actuator: an example of new functionality of actuation, folding and unfolding of electrochemical spring. Sensors and Actuators B: Chemical, 2005. 110(1): p. 120-124.

57. Ogihara, S., et al., Characterization of Pyrrole Copolymer Soft Actuators Prepared by Electrochemical Polymerization Pyrrole and Diethyl 3,4-pyrroledicarboxylate. Molecular Crystals and Liquid Crystals, 2012. 566(1): p. 158-164.

58. Farajollahi, M., et al., Nonlinear Two-Dimensional Transmission Line Models for Electrochemically Driven Conducting Polymer Actuators. IEEE/ASME Transactions on Mechatronics, 2017. 22(2): p. 705-716.

59. Han, G. and G. Shi, Conducting polymer electrochemical actuator made of high-strength threelayered composite films of polythiophene and polypyrrole. Sensors and Actuators B: Chemical, 2004. 99(2): p. 525-531.

60. Otero, T.F. and J.G. Martinez, lonic exchanges, structural movements and driven reactions in conducting polymers from bending artificial muscles. Sensors and Actuators B: Chemical, 2014. 199: p. 27-30.

61. Martinez, J.G., et al., Conducting Polymers as EAPs: How to Start Experimenting with Them, in Electromechanically Active Polymers: A Concise Reference, F. Carpi, Editor. 2016, Springer International Publishing: Cham. p. 1-25.

62. Lewis, T.W., et al., Development of an all-polymer, axial force electrochemical actuator. Synthetic Metals, 1999. 102(1): p. 1317-1318.

63. Madden, J.D., et al., Encapsulated polypyrrole actuators. Synthetic Metals, 1999. 105(1): p. 6164.

64. M. Sansiñena, J., et al., A solid state artificial muscle based on polypyrrole and a solid polymeric electrolyte working in air. Chemical Communications, 1997(22): p. 2217-2218.

65. Kim, S.-S., et al., Electro-active hybrid actuators based on freeze-dried bacterial cellulose and PEDOT:PSS. Smart Materials and Structures, 2013. 22(8): p. 085026.

66. Vidal, F., et al., Long-life air working conducting semi-IPN/ionic liquid based actuator. Synthetic Metals, 2004. 142(1): p. 287-291.

67. Vidal, F., et al., Feasibility of conducting semi-interpenetrating networks based on a poly(ethylene oxide) network and poly(3,4-ethylenedioxythiophene) in actuator design. Journal of Applied Polymer Science, 2003. 90(13): p. 3569-3577.

68. Jager, E.W.H., et al., Patterning and electrical interfacing of individually controllable conducting polymer microactuators. Sensors and Actuators B: Chemical, 2013. 183: p. 283-289. 
69. Galiński, M., A. Lewandowski, and I. Stępniak, Ionic liquids as electrolytes. Electrochimica Acta, 2006. 51(26): p. 5567-5580.

70. Terasawa, N. and K. Asaka, High-performance cellulose nanofibers, single-walled carbon nanotubes and ionic liquid actuators with a poly(vinylidene fluoride-cohexafluoropropylene)/ionic liquid gel electrolyte layer. RSC Advances, 2019. 9(15): p. 82158221.

71. Spinks, G.M., et al., Enhanced control and stability of polypyrrole electromechanical actuators. Synthetic Metals, 2004. 140(2): p. 273-280.

72. Zhou, D., et al., Solid state actuators based on polypyrrole and polymer-in-ionic liquid electrolytes. Electrochimica Acta, 2003. 48(14): p. 2355-2359.

73. Lu, W., et al., Use of Ionic Liquids for $\pi$-Conjugated Polymer Electrochemical Devices. Science, 2002. 297(5583): p. 983-987.

74. Bar-Cohen, Y., Electroactive Polymers as Artificial Muscles - Reality and Challenges. 19th AIAA Applied Aerodynamics Conference, 2001.

75. Festin, N., et al., Robust solid polymer electrolyte for conducting IPN actuators. Smart Materials and Structures, 2013. 22(10): p. 104005.

76. Farajollahi, M., et al., Self-contained tubular bending actuator driven by conducting polymers. Sensors and Actuators A: Physical, 2016. 249: p. 45-56.

77. Khaldi, A., et al., Smarter Actuator Design with Complementary and Synergetic Functions. Advanced Materials, 2015. 27(30): p. 4418-4422.

78. Vidal, F., et al., Long-Life Air Working Semi-IPN/lonic Liquid: New Precursor of Artificial Muscles. Molecular Crystals and Liquid Crystals, 2006. 448(1): p. 95/[697]-102/[704].

79. Hines, L., et al., Soft Actuators for Small-Scale Robotics. Advanced Materials, 2017. 29(13): p. 1603483.

80. Nelson, B.J., I.K. Kaliakatsos, and J.J. Abbott, Microrobots for Minimally Invasive Medicine. Annual Review of Biomedical Engineering, 2010. 12(1): p. 55-85.

81. Mirfakhrai, T., J.D.W. Madden, and R.H. Baughman, Polymer artificial muscles. Materials Today, 2007. 10(4): p. 30-38.

82. Baughman, R.H., Conducting polymer artificial muscles. Synthetic Metals, 1996. 78(3): p. 339353.

83. Põldsalu, I., et al., Thin ink-jet printed trilayer actuators composed of PEDOT:PSS on interpenetrating polymer networks. Sensors and Actuators B: Chemical, 2018. 258: p. 10721079.

84. Alici, G., et al., Conducting polymer microactuators operating in air. Journal of Micromechanics and Microengineering, 2009. 19(2): p. 025017.

85. Smela, E., O. Inganäs, and I. Lundström, Controlled Folding of Micrometer-Size Structures. Science, 1995. 268(5218): p. 1735-1738.

86. Smela, E., et al., Electrochemical muscles: Micromachining fingers and corkscrews. Advanced Materials, 1993. 5(9): p. 630-632.

87. Jager, E.W.H., O. Inganäs, and I. Lundström, Microrobots for Micrometer-Size Objects in Aqueous Media: Potential Tools for Single-Cell Manipulation. Science, 2000. 288(5475): p. 2335-2338.

88. Nguyen, T.N., et al., Ultrathin electrochemically driven conducting polymer actuators: fabrication and electrochemomechanical characterization. Electrochimica Acta, 2018. 265: p. 670-680.

89. $\mathrm{Wu}, \mathrm{Y}$., et al., Fast trilayer polypyrrole bending actuators for high speed applications. Synthetic Metals, 2006. 156(16): p. 1017-1022.

90. Khaldi, A., et al., Conducting interpenetrating polymer network sized to fabricate microactuators. Applied Physics Letters, 2011. 98(16): p. 164101.

91. Maziz, A., et al., Top-down Approach for the Direct Synthesis, Patterning, and Operation of Artificial Micromuscles on Flexible Substrates. ACS Applied Materials \& Interfaces, 2016. 8(3): p. 1559-1564. 
92. Zama, T., et al., Fast and Large Stretching Bis(trifluoromethylsulfonyl)imide (TFSI)-doped Polypyrrole Actuators and Their Applications to Small Devices. Polymer Journal, 2006. 38(7): p. 669-677.

93. Della Santa, A., D. De Rossi, and A. Mazzoldi, Performance and work capacity of a polypyrrole conducting polymer linear actuator. Synthetic Metals, 1997. 90(2): p. 93-100.

94. Spinks, G.M., et al., Strain Response from Polypyrrole Actuators under Load. Advanced Functional Materials, 2002. 12(6 - 7): p. 437-440.

95. Hara, S., et al., TFSI-doped polypyrrole actuator with $26 \%$ strain. Journal of Materials Chemistry, 2004. 14(10): p. 1516-1517.

96. Hara, S., et al., Gel-like Polypyrrole Based Artificial Muscles with Extremely Large Strain. Polymer Journal, 2004. 36(11): p. 933-936.

97. Martinez, J.G. and T.F. Otero, Three electrochemical tools (motor-sensor-battery) with energy recovery work simultaneously in a trilayer artificial muscle. Electrochimica Acta, 2019. 294: p. 126-133.

98. Vidal, F., et al., Poly(3,4-ethylenedioxythiophene)-containing semi-interpenetrating polymer networks: a versatile concept for the design of optical or mechanical electroactive devices. Polymer International, 2010. 59(3): p. 313-320.

99. Binder, W.H. and R. Sachsenhofer, 'Click' Chemistry in Polymer and Material Science: An Update. Macromolecular Rapid Communications, 2008. 29(12 - 13): p. 952-981.

100. Kolb, H.C., M.G. Finn, and K.B. Sharpless, Click Chemistry: Diverse Chemical Function from a Few Good Reactions. Angewandte Chemie International Edition, 2001. 40(11): p. 2004-2021.

101. Rostovtsev, V.V., et al., A Stepwise Huisgen Cycloaddition Process: Copper(I)-Catalyzed Regioselective "Ligation" of Azides and Terminal Alkynes. Angewandte Chemie, 2002. 114(14): p. 2708-2711.

102. Tornøe, C.W., C. Christensen, and M. Meldal, Peptidotriazoles on Solid Phase: [1,2,3]-Triazoles by Regiospecific Copper(I)-Catalyzed 1,3-Dipolar Cycloadditions of Terminal Alkynes to Azides. The Journal of Organic Chemistry, 2002. 67(9): p. 3057-3064.

103. Xi, W., et al., Spatial and Temporal Control of Thiol-Michael Addition via Photocaged Superbase in Photopatterning and Two-Stage Polymer Networks Formation. Macromolecules, 2014. 47(18): p. 6159-6165.

104. Golas, P.L. and K. Matyjaszewski, Marrying click chemistry with polymerization: expanding the scope of polymeric materials. Chemical Society Reviews, 2010. 39(4): p. 1338-1354.

105. Xi, W., et al., Click Chemistry: Click Chemistry in Materials Science (Adv. Funct. Mater. 18/2014). Advanced Functional Materials, 2014. 24(18): p. 2566-2566.

106. Killops, K.L., L.M. Campos, and C.J. Hawker, Robust, efficient, and orthogonal synthesis of dendrimers via thiol-ene "click" chemistry. Journal of the American Chemical Society, 2008. 130(15): p. 5062-5064.

107. Hoyle, C.E. and C.N. Bowman, Thiol-Ene Click Chemistry. Angewandte Chemie International Edition, 2010. 49(9): p. 1540-1573.

108. Hoyle, C.E., A.B. Lowe, and C.N. Bowman, Thiol-click chemistry: a multifaceted toolbox for small molecule and polymer synthesis. Chemical Society Reviews, 2010. 39(4): p. 1355-1387.

109. Cramer, N.B., et al., Investigation of thiol-ene and thiol-ene-methacrylate based resins as dental restorative materials. Dental materials, 2010. 26(1): p. 21-28.

110. Esfandiari, P., et al., Efficient stabilization of thiol - ene formulations in radical photopolymerization. Journal of Polymer Science Part A: Polymer Chemistry, 2013. 51(20): p. 4261-4266.

111. Kaur, S., et al., Metal-free photocatalytic thiol-ene/thiol-yne reactions. Organic \& Biomolecular Chemistry, 2019. 17(7): p. 1955-1961.

112. Salinas, C.N. and K.S. Anseth, Mixed mode thiol- acrylate photopolymerizations for the synthesis of PEG- peptide hydrogels. Macromolecules, 2008. 41(16): p. 6019-6026. 
113. Brink, K.S., P.J. Yang, and J.S. Temenoff, Degradative properties and cytocompatibility of a mixed-mode hydrogel containing oligo [poly (ethylene glycol) fumarate] and poly (ethylene glycol) dithiol. Acta Biomaterialia, 2009. 5(2): p. 570-579.

114. O'Brien, A.K., N.B. Cramer, and C.N. Bowman, Oxygen inhibition in thiol-acrylate photopolymerizations. Journal of Polymer Science Part A: Polymer Chemistry, 2006. 44(6): p. 2007-2014.

115. Lu, H., et al., Investigations of step-growth thiol-ene polymerizations for novel dental restoratives. Dental Materials, 2005. 21(12): p. 1129-1136.

116. Cramer, N.B. and C.N. Bowman, Kinetics of thiol-ene and thiol-acrylate photopolymerizations with real - time fourier transform infrared. Journal of Polymer Science Part A: Polymer Chemistry, 2001. 39(19): p. 3311-3319.

117. Li, G.-Z., et al., Investigation into thiol-(meth) acrylate Michael addition reactions using amine and phosphine catalysts. Polymer Chemistry, 2010. 1(8): p. 1196-1204.

118. Nair, D.P., et al., The thiol-Michael addition click reaction: a powerful and widely used tool in materials chemistry. Chemistry of Materials, 2013. 26(1): p. 724-744.

119. Chan, J.W., et al., Nucleophile-Initiated Thiol-Michael Reactions: Effect of Organocatalyst, Thiol, and Ene. Macromolecules, 2010. 43(15): p. 6381-6388.

120. Chatani, S., D.P. Nair, and C.N. Bowman, Relative reactivity and selectivity of vinyl sulfones and acrylates towards the thiol-Michael addition reaction and polymerization. Polymer Chemistry, 2013. 4(4): p. 1048-1055.

121. Suresh, P. and K. Pitchumani, Per-6-amino-6-cyclodextrin catalyzed asymmetric Michael addition of nitromethane and thiols to chalcones in water. Tetrahedron: Asymmetry, 2008. 19(17): p. 2037-2044.

122. Chan, J.W., C.E. Hoyle, and A.B. Lowe, Sequential Phosphine-Catalyzed, Nucleophilic ThiolEne/Radical-Mediated Thiol- Yne Reactions and the Facile Orthogonal Synthesis of Polyfunctional Materials. Journal of the American Chemical Society, 2009. 131(16): p. 57515753.

123. Nair, D.P., et al., The Thiol-Michael Addition Click Reaction: A Powerful and Widely Used Tool in Materials Chemistry. Chemistry of Materials, 2014. 26(1): p. 724-744.

124. Chan, J.W., et al., The effects of primary amine catalyzed thio-acrylate Michael reaction on the kinetics, mechanical and physical properties of thio-acrylate networks. European Polymer Journal, 2009. 45(9): p. 2717-2725.

125. Chu, C.-M., et al., lodine-catalyzed Michael addition of mercaptans to $\alpha, 6$-unsaturated ketones under solvent-free conditions. Tetrahedron letters, 2005. 46(30): p. 4971-4974.

126. Northrop, B.H., S.H. Frayne, and U. Choudhary, Thiol-maleimide "click" chemistry: evaluating the influence of solvent, initiator, and thiol on the reaction mechanism, kinetics, and selectivity. Polymer Chemistry, 2015. 6(18): p. 3415-3430.

127. Hoyle, C.E., T.Y. Lee, and T. Roper, Thiol-enes: Chemistry of the past with promise for the future. Journal of Polymer Science Part A: Polymer Chemistry, 2004. 42(21): p. 5301-5338.

128. Hoyle, C.E., T.Y. Lee, and T. Roper, Thiol-enes: Chemistry of the past with promise for the future. Journal of Polymer Science Part A: Polymer Chemistry, 2004. 42(21): p. 5301-5338.

129. Morgan, C.R., F. Magnotta, and A.D. Ketley, Thiol/ene photocurable polymers. Journal of Polymer Science: Polymer Chemistry Edition, 1977. 15(3): p. 627-645.

130. Ligon, S.C., et al., Strategies to Reduce Oxygen Inhibition in Photoinduced Polymerization. Chemical Reviews, 2014. 114(1): p. 557-589.

131. Dong, X., et al., Carbanion as a Superbase for Catalyzing Thiol-Epoxy Photopolymerization. Polymers, 2017. 9(9): p. 400.

132. Bouzrati-Zerelli, M., et al., Design of novel photobase generators upon violet LEDs and use in photopolymerization reactions. Polymer, 2017. 124: p. 151-156.

133. Blasco, E., M. Wegener, and C. Barner-Kowollik, Photochemically Driven Polymeric Network Formation: Synthesis and Applications. Advanced Materials, 2017. 29(15): p. 1604005. 
134. Zhang, X., et al., Visible-Light-Initiated Thiol-Michael Addition Polymerizations with CoumarinBased Photobase Generators: Another Photoclick Reaction Strategy. ACS Macro Letters, 2016. 5(2): p. 229-233.

135. Zandi Shafagh, R., et al., E-Beam Nanostructuring and Direct Click Biofunctionalization of ThiolEne Resist. ACS Nano, 2018. 12(10): p. 9940-9946.

136. Sandström, N., et al., Reaction injection molding and direct covalent bonding of OSTE+ polymer microfluidic devices. Journal of Micromechanics and Microengineering, 2015. 25(7): p. 075002.

137. Wendeln, C., et al., Photochemical Microcontact Printing by Thiol-Ene and Thiol-Yne Click Chemistry. Langmuir, 2010. 26(20): p. 15966-15971.

138. Hillmering, M., et al., Off-stoichiometry improves the photostructuring of thiol-enes through diffusion-induced monomer depletion. Microsystems \&Amp; Nanoengineering, 2016. 2: p. 15043.

139. Wolfberger, A., et al., Ring Opening Metathesis Polymerization Derived Polymers as Photoresists: Making Use of Thiol-ene Chemistry. Macromolecular Rapid Communications, 2011. 32(6): p. 518-522.

140. Schenk, V., et al., Water-Developable Poly(2-oxazoline)-Based Negative Photoresists. Macromolecular Rapid Communications, 2012. 33(5): p. 396-400.

141. Qin, D., Y. Xia, and G.M. Whitesides, Soft lithography for micro- and nanoscale patterning. Nature Protocols, 2010. 5(3): p. 491-502.

142. Faustino, V., et al., Biomedical microfluidic devices by using low-cost fabrication techniques: $A$ review. Journal of Biomechanics, 2016. 49(11): p. 2280-2292.

143. Zhou, Q. and T. Kim, Review of microfluidic approaches for surface-enhanced Raman scattering. Sensors and Actuators B: Chemical, 2016. 227: p. 504-514.

144. Bou, S.J.M.C. and A.V. Ellis, Microfluidic devices using thiol-ene polymers. SPIE Micro+Nano Materials, Devices, and Applications. Vol. 8923. 2013: SPIE.

145. Carlborg, C.F., et al., Beyond PDMS: off-stoichiometry thiol-ene (OSTE) based soft lithography for rapid prototyping of microfluidic devices. Lab on a Chip, 2011. 11(18): p. 3136-3147.

146. Wang, X., et al., 3D printing of polymer matrix composites: $A$ review and prospective. Composites Part B: Engineering, 2017. 110: p. 442-458.

147. Roppolo, I., et al., Thiol-yne chemistry for 3D printing: exploiting off stoichiometric route for selective functionalization of 3D objects. Polymer Chemistry, 2019.

148. Deng, S., et al., Rapid Open-Air Digital Light 3D Printing of Thermoplastic Polymer. Advanced Materials, 2019. 31(39): p. 1903970.

149. Chen, L., et al., Highly stable thiol-ene systems: from their structure-property relationship to DLP 3D printing. Journal of Materials Chemistry C, 2018. 6(43): p. 11561-11568.

150. Le Bideau, J., L. Viau, and A. Vioux, lonogels, ionic liquid based hybrid materials. Chemical Society Reviews, 2011. 40(2): p. 907-925.

151. Wang, J., et al., Recent development of ionic liquid membranes. Green Energy \& Environment, 2016. 1(1): p. 43-61.

152. Long, T.E., Y.A. Elabd, and J. Yuan, Ionic Liquids in Polymer Design. Macromolecular Rapid Communications, 2016. 37(14): p. 1105-1105.

153. Welton, T., Room-temperature ionic liquids. Solvents for synthesis and catalysis. Chemical reviews, 1999. 99(8): p. 2071-2084.

154. Rogers, R.D. and K.R. Seddon, lonic liquids--solvents of the future? Science, 2003. 302(5646): p. 792-793.

155. Vioux, A. and B. Coasne, From lonogels to Biredox lonic Liquids: Some Emerging Opportunities for Electrochemical Energy Storage and Conversion Devices. Advanced Energy Materials, 2017. 7(22): p. 1700883.

156. Liu, X., et al., Tough Nanocomposite lonogel-based Actuator Exhibits Robust Performance. Scientific Reports, 2014. 4: p. 6673.

157. Chen, N., et al., lonogel Electrolytes for High-Performance Lithium Batteries: A Review. Advanced Energy Materials, 2018. 8(12): p. 1702675. 
158. Néouze, M.-A., et al., lonogels, New Materials Arising from the Confinement of lonic Liquids within Silica-Derived Networks. Chemistry of Materials, 2006. 18(17): p. 3931-3936.

159. Andrzejewska, E., A. Marcinkowska, and A. Zgrzeba, lonogels-materials containing immobilized ionic liquids. Polimery, 2017. 62(5): p. 344--352.

160. Ishii, S., et al., Tetra-PEG Network Containing Ionic Liquid Synthesized via Michael Addition Reaction and Its Application to Polymer Actuator. Macromolecules, 2017. 50(7): p. 2906-2915.

161. Lai, J., et al., Highly Stretchable, Fatigue-Resistant, Electrically Conductive, and TemperatureTolerant lonogels for High-Performance Flexible Sensors. ACS Applied Materials \& Interfaces, 2019. 11(29): p. 26412-26420.

162. Andrzejewska, E., Photoinitiated polymerization in ionic liquids and its application. Polymer International, 2017. 66(3): p. 366-381.

163. Matsumoto, K. and T. Endo, Confinement of Ionic Liquid by Networked Polymers Based on Multifunctional Epoxy Resins. Macromolecules, 2008. 41(19): p. 6981-6986.

164. Stępniak, I. and E. Andrzejewska, Highly conductive ionic liquid based ternary polymer electrolytes obtained by in situ photopolymerisation. Electrochimica Acta, 2009. 54(24): p. 5660-5665.

165. Vioux, A., et al., Use of ionic liquids in sol-gel; ionogels and applications. Comptes Rendus Chimie, 2010. 13(1): p. 242-255.

166. Young, W.-S. and T.H. Epps, Ionic Conductivities of Block Copolymer Electrolytes with Various Conducting Pathways: Sample Preparation and Processing Considerations. Macromolecules, 2012. 45(11): p. 4689-4697.

167. He, Y., et al., Ion Gels by Self-Assembly of a Triblock Copolymer in an Ionic Liquid. The Journal of Physical Chemistry B, 2007. 111(18): p. 4645-4652.

168. He, Y. and T.P. Lodge, A thermoreversible ion gel by triblock copolymer self-assembly in an ionic liquid. Chemical Communications, 2007(26): p. 2732-2734.

169. Oubaha, M., et al., Graphene-doped photo-patternable ionogels: tuning of conductivity and mechanical stability of 3D microstructures. Journal of Materials Chemistry, 2012. 22(21): p. 10552-10559.

170. Yeon, S.-H., et al., Characterization of PVdF(HFP) Gel Electrolytes Based on 1-(2-Hydroxyethyl)3-methyl Imidazolium Ionic Liquids. The Journal of Physical Chemistry B, 2005. 109(38): p. 17928-17935.

171. Zheng, S., et al., lonic liquid pre-intercalated MXene films for ionogel-based flexible microsupercapacitors with high volumetric energy density. Journal of Materials Chemistry A, 2019. 7(16): p. 9478-9485.

172. del Agua, I., et al., Conducting Polymer longels Based on PEDOT and Guar Gum. ACS Macro Letters, 2017. 6(4): p. 473-478.

173. Villar-Chavero, M.M., et al., Tuning the rheological properties of cellulosic ionogels reinforced with chitosan: The role of the deacetylation degree. Carbohydrate Polymers, 2019. 207: p. 775781.

174. Zgrzeba, A., E. Andrzejewska, and A. Marcinkowska, lonic liquid - containing ionogels by thiolene photopolymerization. Kinetics and solvent effect. RSC Advances, 2015. 5(121): p. 100354100361.

175. Lu, J., F. Yan, and J. Texter, Advanced applications of ionic liquids in polymer science. Progress in Polymer Science, 2009. 34(5): p. 431-448.

176. Zhong, Y., et al., Highly Conductive, Photolithographically Patternable lonogels for Flexible and Stretchable Electrochemical Devices. ACS Applied Materials \& Interfaces, 2018. 10(25): p. 21601-21611.

177. Lee, S.-K., et al., Photo-patternable ion gel-gated graphene transistors and inverters on plastic. Nanotechnology, 2013. 25(1): p. 014002.

178. Choi, J.-H., et al., High Capacitance, Photo-Patternable Ion Gel Gate Insulators Compatible with Vapor Deposition of Metal Gate Electrodes. ACS Applied Materials \& Interfaces, 2014. 6(21): p. 19275-19281. 
179. Farsari, M., M. Vamvakaki, and B.N. Chichkov, Multiphoton polymerization of hybrid materials. Journal of Optics, 2010. 12(12): p. 124001.

180. Kavanagh, A., et al., Photo-patternable hybrid ionogels for electrochromic applications. Journal of Materials Chemistry, 2011. 21(24): p. 8687-8693.

181. Kurselis, K., et al., 3D fabrication of all-polymer conductive microstructures by two photon polymerization. Optics Express, 2013. 21(25): p. 31029-31035.

182. Cheng, X., et al., Gel Polymer Electrolytes for Electrochemical Energy Storage. Advanced Energy Materials, 2018. 8(7): p. 1702184.

183. Trivedi, T.J., et al., Functionalized Agarose Self-Healing lonogels Suitable for Supercapacitors. ChemSusChem, 2015. 8(19): p. 3294-3303.

184. Cao, Y., et al., A Transparent, Self-Healing, Highly Stretchable lonic Conductor. Advanced Materials, 2017. 29(10): p. 1605099.

185. Cho, Y.-G., et al., Gel/Solid Polymer Electrolytes Characterized by In Situ Gelation or Polymerization for Electrochemical Energy Systems. Advanced Materials, 2019. 31(20): p. 1804909.

186. Tibbits, A.C., Y.S. Yan, and C.J. Kloxin, Covalent Incorporation of Ionic Liquid into Ion-Conductive Networks via Thiol-Ene Photopolymerization. Macromolecular Rapid Communications, 2017. 38(13): p. 1700113.

187. Zhang, Y., et al., A gel single ion polymer electrolyte membrane for lithium-ion batteries with wide-temperature range operability. RSC Advances, 2014. 4(40): p. 21163-21170.

188. Rohan, R., et al., Melamine-terephthalaldehyde-lithium complex: a porous organic network based single ion electrolyte for lithium ion batteries. Journal of Materials Chemistry A, 2015. 3(9): p. 5132-5139.

189. Tibbits, A.C., Y.S. Yan, and C.J. Kloxin, Covalent Incorporation of Ionic Liquid into Ion Conductive Networks via Thiol - Ene Photopolymerization. Macromolecular rapid communications, 2017. 38(13): p. 1700113.

190. Thiemann, S., et al., Cellulose - based ionogels for paper electronics. Advanced Functional Materials, 2014. 24(5): p. 625-634.

191. Kavanagh, A., et al., Stimuli responsive ionogels for sensing applications-an overview. Membranes, 2012. 2(1): p. 16-39.

192. Terasawa, N. and K. Asaka, High-Performance PEDOT:PSS/Single-Walled Carbon Nanotube/Ionic Liquid Actuators Combining Electrostatic Double-Layer and Faradaic Capacitors. Langmuir, 2016. 32(28): p. 7210-7218.

193. Terasawa, N. and K. Asaka, Electrochemical and electromechanical properties of superiorperformance hybrid polymer actuators exhibiting synergistic effects due to manganese oxide and multi-walled carbon nanotubes on various ionic liquids. RSC Advances, 2016. 6(70): p. 66360-66367.

194. Fukushima, T., et al., Molecular Ordering of Organic Molten Salts Triggered by Single-Walled Carbon Nanotubes. Science, 2003. 300(5628): p. 2072-2074.

195. Chen, B., et al., Highly Stretchable and Transparent lonogels as Nonvolatile Conductors for Dielectric Elastomer Transducers. ACS Applied Materials \& Interfaces, 2014. 6(10): p. 78407845.

196. Yuan, J., D. Mecerreyes, and M. Antonietti, Poly(ionic liquid)s: An update. Progress in Polymer Science, 2013. 38(7): p. 1009-1036.

197. Qian, W., J. Texter, and F. Yan, Frontiers in poly(ionic liquid)s: syntheses and applications. Chemical Society Reviews, 2017. 46(4): p. 1124-1159.

198. Carlotti, M. and V. Mattoli, Functional Materials for Two-Photon Polymerization in Microfabrication. Small. 0(0): p. 1902687.

199. Puce, S., et al., 3D-microfabrication by two-photon polymerization of an integrated sacrificial stencil mask. Micro and Nano Engineering, 2019. 2: p. 70-75. 
200. Maziz, A., et al., Knitting and weaving artificial muscles. Science Advances, 2017. 3(1): p. e1600327. 


\section{Papers}

The papers associated with this thesis have been removed for copyright reasons. For more details about these see:

http://urn.kb.se/resolve?urn=urn:nbn:se:liu:diva-161360 


\section{FACULTY OF SCIENCE AND ENGINEERING}

Linköping Studies in Science and Technology, Dissertation No. 2025, 2019

Department of Physics, Chemistry and Biology

Linköping University

SE-581 83 Linköping, Sweden

www.liu.se 